\title{
热活化延迟苂光蓝光小分子取代基效应的研究进展
}

\author{
周涛 $a$ 钱越 $a$ 王宏健 $a$ 冯全友*, $a$ 解令海*, $a$ 黄维 $a, b$ \\ ( ${ }^{a}$ 南京邮电大学信息材料与纳米技术研究院 有机电子与信息显示国家重点实验室 南京 210023) \\ ( $b$ 西北工业大学柔性电子前沿科学中心 柔性电子材料与器件工信部重点实验室 西安 710072)
}

\begin{abstract}
摘要 近年来, 作为第三代有机发光二极管(organic light-emitting diodes, OLED)发光材料的热活化延迟荧光(thermally activated delayed fluorescence, TADF)材料受到了学术界和产业界的广泛关注. TADF 分子由于其单线态与三线态之间的 能级差较小, 三线态激子可以被环境热活化而通过反系间窝越上转换至单线态，理论上可实现 $100 \%$ 的激子利用率，从 而使得 OLED 器件外量子效率显著提高. TADF 材料被认为是突破高效稳定有机电致蓝光发射瓶颈的潜在解决方案. 一般, TADF 分子为含有电子给体(donor, D)和电子受体(acceptor, A)的纯有机推拉电子体系. 通过改变给体单元和受体 单元的结构、数量和取代基及其位置可以有效调节 TADF 分子的单线态-三线态能级差、前线轨道分布、聚集态结构、 电致发光颜色及其性能. 同时取代基在调控给、受体单元的推拉电子能力及 TADF 材料的分子构型、聚集态结构和稳 定性等物化特性方面扮演着非常重要的角色. 本综述分别对 D-A 型和多重共振型 TADF 蓝光分子的取代基效应进行了 综述, 以期为高效稳定的蓝光 TADF 分子的设计合成提供有效借鉴.
\end{abstract}

关键词＼cjkstart蓝光发光体; 热活化延迟荧光; 小分子; 取代基; 有机发光二极管

\section{Recent Advances in Substituent Effects of Blue Thermally Activated Delayed Fluorescence Small Molecules}

\author{
Tao Zhou ${ }^{a}$ Yue Qian ${ }^{a}$ Hongjian Wang $^{a}$ Quanyou Feng*,a Linghai Xie*,a $^{*}$ Wei Huang ${ }^{a, b}$ \\ $\left({ }^{a}\right.$ State Key Laboratory of Organic Electronics and Information Displays \& Institute of Advanced Materials (IAM), \\ Nanjing University of Posts \& Telecommunications, Nanjing 210023, China) \\ $\left({ }^{b}\right.$ Frontiers Science Center for Flexible Electronics (FSCFE), MIIT Key Laboratory of Flexible Electronics (KLoFE), \\ Northwestern Polytechnical University, Xi'an 710072, China)
}

\begin{abstract}
As the third-generation emitters for organic light-emitting diodes (OLED), thermally activated delayed fluorescence (TADF) materials have attracted widespread attention from both academic and industrial communities in recent years. In TADF molecules, the triplet excitons can be upconverted to the singlet state with the aid of ambient thermal energy by virtue of the reverse intersystem crossing (RISC) owing to the small singlet-triplet splitting energy $\left(\Delta E_{\mathrm{ST}}\right)$. Therefore, $100 \%$ exciton utilization efficiency can be theoretically realized by harvesting both singlet and triplet excitons. Consequently, the external quantum efficiencies of OLEDs can be significantly improved compared with the first-generation devices based on conventional fluorophores. TADF materials are regarded as an effective potential solution to break through the bottleneck of highly efficient and stable blue organic electroluminescence (EL). Generally, TADF molecules is a purely organic push and pull system containing at least an electronic donor and acceptor. The $\Delta E_{\mathrm{ST}}$, frontier orbital distributions, aggregation structures, EL colors and device performance can be effectively tuning by changing the structures and quantities of the donor and the acceptor, the substituents and their substituted positions. Meanwhile, the substituents of TADF molecules play a crucial role in the regulation of the strengths of donor and acceptor, molecular configurations, aggregation structures, stabilities and other physical and chemical properties. The substituent effects of purely organic blue TADF molecules from D-A type and multiple-resonance type blue TADF molecules are summarized, in the hope of providing effective reference for the design and synthesis of high-efficiency and stable blue light TADF molecules.
\end{abstract}

Keywords blue emitter; thermally activated delayed fluorescence; small molecule; substituent; OLED

\section{1 引言}

自 1987 年 Tang 和 VanSlyke $e^{[1]}$ 报道的开创性工作以 来，有机发光二极管 (organic light-emitting diodes,
OLED)已经取得了长足的发展. OLED 具有视角宽、成 本低、质量轻、功耗小、色纯度高、响应速度快以及易 于实现柔性等众多优点, 在全色信息显示和固态照明等 领域表现出巨大的应用前景 ${ }^{[2-4]}$, 并在智能手机、电视机

*E-mail: iamqyfeng@njupt.edu.cn; iamlhxie@njupt.edu.cn

Received January 13, 2021; published February 26, 2021.

Project supported by the Natural Science Foundation of Jiangsu Province (No. BK20190090) and the National Natural Science Foundation of China (No. 21774061).

项目受江苏省自然科学基金(No. BK20190090)和国家自然科学基金(No. 21774061)资助. 
和计算机显示器等产业领域占据的市场份额逐步上升. 在有机电致发光器件中, 电驱动产生的激子可分别通过 单线态和三线态辐射至基态 $\left(\mathrm{S}_{0}\right)$ 发射出不同类型的光, 即苂光和磷光. 由于受到自旋统计理论的限制, 产生的 单线态和三线态激子比例约为 $1: 3$, 即分别占总激子 数的 $25 \%$ 和 $75 \%{ }^{[5-6]}$. 正因为如此, 如图 1 所示, 第一代 荧光 OLED 只能利用单线态激子, 而三线态激子以非辐 射失活的形式回到 $\mathrm{S}_{0}$ 态, 导致器件的理论内量子效率 (internal quantum efficiency, IQE) 最高仅为 $25 \%{ }^{[7]}$. 根据 公式 $\mathrm{EQE}=\eta \cdot \mathrm{IQE}(\mathrm{EQE}$ 为外量子效率, $\eta$ 为光输出耦合 效率), 即使输出耦合效率达到 30\%, OLED 的 EQE 范围 也最多为 $5 \%$ 至 $7.5 \%{ }^{[8]}$, 较大程度限制其推广应用.

1998 年, Ma 研究组 ${ }^{[5]}$ 和 Forrest 研究组 ${ }^{[6]}$ 分别报道了 基于金属有机磷光材料的 OLED, 由于锇、铂等过渡族 金属离子具有较强的自旋轨道耦合效应, 单线态和三线 态激子都能被利用, 因此理论上可实现 $100 \%$ 的 $\mathrm{IQE}^{[9-11]}$. 与苂光材料相比, 基于磷光发射体的器件具有 相对较低的驱动电压, 较高的 EQE, 显著的斯托克斯位 移, 易调节的发光颜色等优异的光物理性质 ${ }^{[12-13]}$, 但是 也存在由贵金属导致的价格高昂、污染环境等不足; 通 常基于有机磷光材料的发光器件存在三线态-三线态湮 灭(triplet-triplet annihilation, TTA), 导致器件效率下降, 稳定性变差 ${ }^{[14]}$, 特别是蓝色磷光 OLED 材料的器件效率 和寿命长期达不到产业的要求 ${ }^{[15]}$.

近年来, Adachi 等 ${ }^{[16-17]}$ 报道了被称之为第三代 OLED 材料的热活化延迟苂光(thermally activated delayed fluorescence, TADF)材料. 如图 1 所示, 发光分子
的 $\mathrm{S}_{1}$ 态能量高于 $\mathrm{T}_{1}$ 态，当两者的能级差 $\left(\Delta E_{\mathrm{ST}}\right)$ 足够小 时，易发生反系间窝越(reverse intersystem crossing, RISC), $\mathrm{T}_{1}$ 态激子通过吸收环境热上转换到 $\mathrm{S}_{1}$ 态. $\mathrm{S}_{1}$ 态的 激子迅速辐射失活产生瞬时荧光(prompt fluorescence, $\mathrm{PF}), \mathrm{T}_{1}$ 态激子通过 RISC 过程上转换到 $\mathrm{S}_{1}$ 态后辐射失活 发出延迟苂光(delayed fluorescence, DF), 理论上可以实 现 $100 \%$ 的 $\mathrm{IQE}^{[18-21]}$. 目前，红、绿、蓝 TADF 型电致发 光器件的最高外量子效率 $\left(\mathrm{EQE}_{\max }\right)$ 分别可达 $25.2 \%$ [22]、 $37.8 \%{ }^{[23]} 、 38.2 \%{ }^{[24]}$, 可比肩甚至超越第二代磷光 OLED, 被学术界和产业界寄予厚望. 其中，蓝光材料综合性能 的改善不仅可以显著提升信息显示和照明器件的工作 稳定性、色纯度, 而且能有效降低能耗, 节约成本 ${ }^{[25]}$. 然而, 当前能达到美国国家电视标准委员会(NTSC)标 准 (CIE 坐标值 $x+y<0.30$, 且 $y<0.08)$ 和欧洲广播联盟 (EBU)标准 $(\mathrm{CIE}$ 坐标 $y<0.06)$ 的高效稳定的标准蓝光材 料依然十分贵乏 ${ }^{[26]}$. 因此与无机发光二极管一样, 要进 一步推进 TADF 型 OLED 的产业化进程，高效稳定蓝光 TADF 材料的研制至关重要.

在蓝光 TADF 材料的设计合成中, 各类取代基常被 用来调节目标分子的溶解性、稳定性、单线态-三线态 能级差、前线轨道分布、激发态寿命、聚集态结构、电 致发光颜色及其 OLED 性能等. 例如, 利用大体积的取 代基增大发光单元间的分子间距，有效抑制了聚集诱导 的苂光猝灭 ${ }^{[27]}$; 不同长度的烷氧基链对发光分子的光 物理性质影响显著 ${ }^{[28]}$. 因此，选取合适的取代基会对蓝 光 TADF 材料的物化性质及其器件性能的调控等起到举 足轻重的作用，是实现高效稳定的纯有机电致蓝光发射

\section{Three Generations OLEDs}
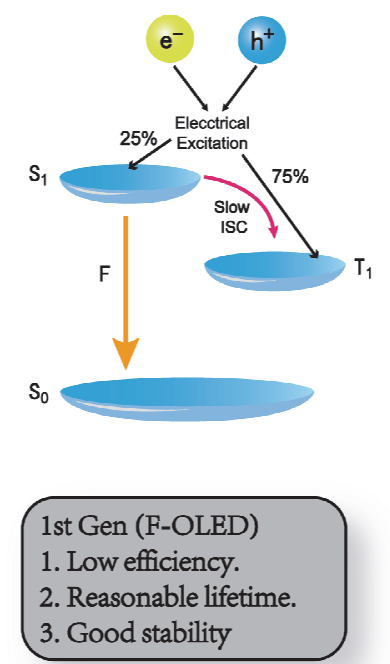

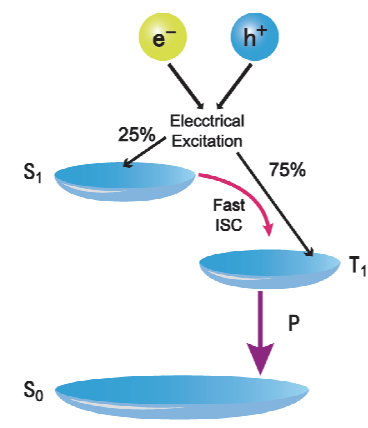

2nd Gen (Ph-OLED)

1. High efficiency.

2. Short lifetime for Blue.

3. High cost.

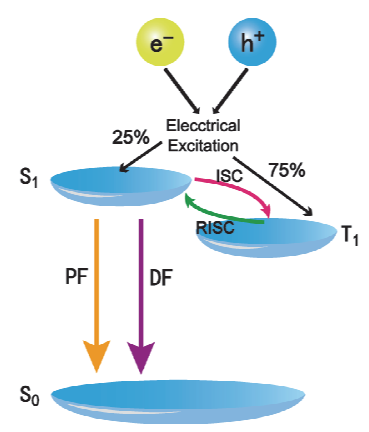

3rd Gen (TADF-OLED)

1. High efficiency.

2. No heavy atom.

3. Short lifetime for Blue.

图 1 三代有机发光二极管发光材料的光物理过程及优缺点

Figure 1 Electroluminescent processes, merits and demerits of three generations OLED emitter 
的重要手段. 本综述将首先介绍蓝光 TADF 分子的设计 策略, 然后分别从 D-A 型蓝光 TADF 分子以及多重共振 型蓝光 TADF 分子方面对 TADF 分子的取代基效应进行 了综述, 期望为高效稳定的蓝光 TADF 分子的设计合成 提供有效借鉴.

\section{2 蓝光 TADF 小分子的设计策略}

近年来, 尽管 TADF 材料及其 OLED 器件的研究取 得了长足进展, 但是高性能、高稳定性蓝光 TADF 分子 的设计开发依然面临严峻挑战. 众所周知, 发光分子的 物理化学性质和电致发光性能与其电子结构、空间位 阻、构象与拓扑以及超分子弱作用能密切相关 ${ }^{[29]}$. 科研 人员在丰富的分子设计合成经验的基础上, 借助分子模 拟等理论计算方法进行 TADF 分子设计, 这为上述挑战 提供了有效的解决方案 ${ }^{[30]}$. 在 TADF 分子的理论研究 中, 密度泛函理论 (DFT) 和含时间密度泛函理论 (TDDFT $)^{[31]}$ 等方法常用于计算模拟发光分子的二面角、 前线轨道、基态能级、跃迁偶极矩、局域激发态和电荷 转移激发态能级等基态和激发态性质 ${ }^{[32-34]}$.

此外, 为了提高分子的设计开发效率, Gomez 等 ${ }^{[35]}$ 开发了一种虚拟笁选方法. 根据 Parker 等[36]提出的动力 学平衡模型, 计算发现 TADF 分子要求荧光速率 $\left(k_{\mathrm{F}}\right)<<$ 反系间窝越速率 $\left(k_{\text {RISC }}\right)$. Gibson 等[37]利用量子动力学解 释 $\mathrm{TADF}$ 自旋振动机制. 上述理论计算方法和手段对 $\mathrm{TADF}$ 分子的设计开发均具有重要的指导意义.

对于 TADF 分子来说, 要使得三线态激子能够在环 境热的刺激下高效地反系间窝越至单线态从而发出纯 蓝延迟苂光, $\mathrm{S}_{1}$ 与 $\mathrm{T}_{1}$ 之间能级差 $\Delta E_{\mathrm{ST}}$ 必须足够小 ${ }^{[38]}$. $\Delta E_{\mathrm{ST}}$ 的减小能够提高反系间䇀越速率, 因此尽可能地 减小 $\Delta E_{\mathrm{ST}}$ 对促进反系间窝越过程非常重要. 而通过控 制最高占据分子轨道(highest occupied molecular orbital, HOMO)和最低末占分子轨道(lowest unoccupied molecular orbital, LUMO)能级的有效分离可以满足该要求. 通常, 纯有机 TADF 分子是含有电子给体(donor, D) 和电 子受体(acceptor, A) 的推拉电子体系. 一般, HOMO 能级 分布主要受给体单元影响, LUMO 能级分布主要由受体 单元支配 ${ }^{[39-40]}$. 因而可以选择适当的给受体单元和连接 方式以获得较大的扭曲二面角和调控前线轨道能级的 分离程度, 保证足够小的交换能.

然而, 在追求更为高效的蓝光尤其是深蓝光 TADF 材料时面临着一个本征的矛盾, 即实现高效 TADF 过程 要求减小 $\mathrm{HOMO}$ 与 $\mathrm{LUMO}$ 的重叠程度来降低 $\Delta E_{\mathrm{ST}}$, 分 子给受体之间需要保持较大的二面角, 同时需要增强分 子内电荷转移(ICT); 但蓝光或深蓝光发射又必须要弱 化 ICT 以抑制结构弛豫和光谱红移. 此外, 为了确保纯 蓝光发射, 还需要适当地减小给受体之间的二面角度 数, 从而减弱给受体的给电子和吸电子能力. 换言之, 蓝光 TADF 分子设计理念与其高效的要求是冲突的, 因
此也使得设计高效蓝光 TADF 分子带来了巨大的挑战 性. 为了获得高效蓝光、特别是深蓝光 $\mathrm{TADF}^{[41-43]}$, 一般 遵循以下几个原则: (1) 削弱分子内电荷转移(charge transfer, CT)态; (2) 分子体系同时满足弱 ICT 特性和小 的前线分子轨道重叠以实现小的电子交换能; (3) 需要 具有较大的跃迁偶极矩与分子刚性，以实现高的光致发 光量子产率(PLQY); (4) 要求局域三线态 ( $\left.{ }^{3} \mathrm{LE}\right)$ 能级不能 明显低于电荷转移三线态 $\left({ }^{3} \mathrm{CT}\right)$ 能级. 较理想的情况为 分子的电荷转移单线态 $\left({ }^{1} \mathrm{CT}\right) 、{ }^{3} \mathrm{CT}$ 和 ${ }^{3} \mathrm{LE}$ 具有近似简并 的能级排列 ${ }^{[25]}$. 在图 2 中, 我们简单总结了一些常用的 蓝光 TADF 分子设计规则.

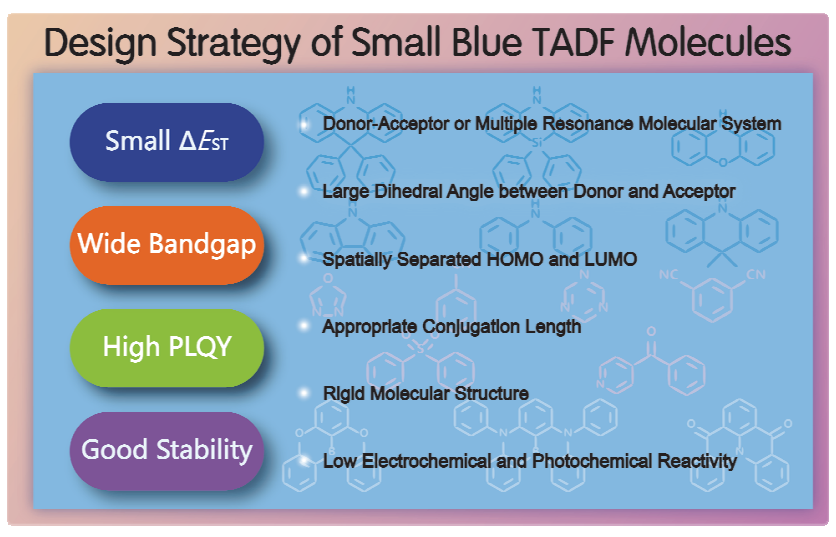

图 2 高效蓝光 TADF 小分子的设计策略

Figure 2 Design strategy for high-efficiency small blue TADF molecules

\section{D-A 型蓝光 TADF 小分子的取代基效应}

在 D-A 型 TADF 分子中, 将给体与受体单元以一定 的方式链接成推拉电子体系, 能够实现 $\mathrm{HOMO}$ 与 LUMO 的有效分离. 目前, 常用于构筑 D-A 型 TADF 材 料的电子给体主要是具有较强的给电子能力、高的三线 态能级、较好的稳定性以及合成方法简单等特点的芳胺 构筑单元，如咔唑、苯胺、鲐啶、吩啞嗪及其衍生物

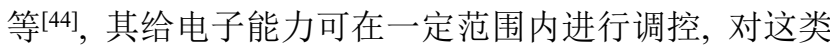
基团的研究也相对成熟. 常见的受体单元主要包括氰 基、嘧啶、三嗪、膦氧基团和羰基等，不仅种类繁多，而 且电子和空间效应也丰富多样. 将不同取代基团引入给 受体单元不仅可以调节其强度, 调控分子的单线态和三 线态能级，构筑由空间位阻引起的不同扭曲二面角，还 可以有效改善分子的溶解性和热稳定性，可以进一步调 节分子的光电特性, 甚至可以改变发光机制, 从 TADF 机制转变为室温磷光 (RTP)机制 ${ }^{[45]}$, 或从 RTP 变成 $\mathrm{TADF}^{[46]}$, 进而影响其发光器件的各性能参数与使用寿 命. 我们将根据电子受体对 D-A 型蓝光 TADF 分子进行 分类, 分别从电子给体、共轭桥和电子受体角度总结了 取代基团的引入对发光分子的物化性质及其器件性能 的影响. 所述的蓝光 TADF 小分子材料及其 OLED 器件 光电性质数据列于表 1 . 
表 1 D-A 型蓝光 TADF 分子的热学、光物理性质和 OLED 器件性能

Table 1 Thermal and photophysical properties and OLED performance of D-A blue TADF molecules

\begin{tabular}{|c|c|c|c|c|c|c|c|c|}
\hline Emitter & $\begin{array}{c}T_{\mathrm{g}} / T_{\mathrm{d}} \\
/{ }^{\circ} \mathrm{C} \\
\end{array}$ & $\lambda_{\mathrm{PL}} / \mathrm{nm}$ & $\begin{array}{l}\mathrm{PLQY}^{d} / \% \\
\text { (Sol./film) }\end{array}$ & $\Delta E_{\mathrm{ST}} / \mathrm{eV}$ & $\lambda_{\mathrm{EL}} / \mathrm{nm}$ & CIE & $\mathrm{EQE} / \%$ & Ref. \\
\hline $\mathrm{C1}$ & $-/ 285$ & $437^{a}$ & $39 /-$ & - & 456 & $(0.15,0.12)$ & $\leqslant 1$ & [48] \\
\hline $\mathrm{C2}$ & $86 / 285$ & $460^{a}$ & $18 /-$ & - & 472 & $(0.16,0.24)$ & 5.05 & [48] \\
\hline C3 & $316 / 436$ & $442^{a}$ & $49 /-$ & $0.30^{a, f}$ & - & $(0.17,0.20)$ & 10.6 & [49] \\
\hline C4 & $322 / 454$ & $456^{a}$ & $68 /-$ & $0.24^{a, f}$ & - & $(0.16,0.22)$ & 16.2 & [49] \\
\hline $\mathrm{C5}$ & 318/- & $464^{a}$ & $70 /-$ & $0.22^{a, f}$ & - & $(0.22,0.40)$ & 16.7 & [49] \\
\hline C6 & $325 /-$ & $480^{a}$ & $86 /-$ & $0.17^{a, f}$ & - & $(0.21,0.41)$ & 21.2 & [49] \\
\hline C7 & $-/ 368$ & $403^{a}$ & $13 / 28$ & $0.31^{a, f}$ & 418 & $(0.15,0.05)$ & 2.5 & {$[50]$} \\
\hline C8 & $-/ 375$ & $417^{a}$ & $34 / 66$ & $0.22^{a, f}$ & 436 & $(0.15,0.07)$ & 7.7 & [50] \\
\hline C9 & $-/ 397$ & $414^{a}$ & $32 / 76$ & $0.26^{a, f}$ & 428 & $(0.16,0.06)$ & 10.3 & {$[50]$} \\
\hline $\mathrm{C10}$ & $-/ 417$ & $460^{a}$ & $83 / 86$ & $0.14^{a, f}$ & 468 & $(0.16,0.23)$ & 18 & {$[50]$} \\
\hline C11 & $-/-$ & $480^{a}$ & $85 /-$ & $0.17^{a, f}$ & - & - & - & [51] \\
\hline $\mathrm{C} 12$ & $-/-$ & $480^{a}$ & $81 / 80$ & $0.15^{a, f}$ & - & $(0.21,0.44)$ & 20.9 & {$[51]$} \\
\hline C13 & $-/ 354$ & $453^{\mathrm{a}}$ & $40 / 51$ & $0.19^{a, f}$ & 461 & $(0.21,0.44)$ & 13.8 & [52] \\
\hline C14 & $-/ 351$ & $470^{\mathrm{a}}$ & $44 / 74$ & $0.07^{a, f}$ & 476 & $(0.21,0.44)$ & 23.8 & [52] \\
\hline B1 & $58 / 303$ & $465^{b}$ & $-/ 61^{c}$ & $0.06^{c, f}$ & 463 & $(0.15,0.17)^{g}$ & $8^{g}$ & [53] \\
\hline B2 & $105 / 280$ & $476^{b}$ & $-/ 94^{c}$ & $0.05^{c, f}$ & 474 & $(0.15,0.26)^{g}$ & $19.1^{g}$ & [53] \\
\hline B3 & $-/-$ & $463^{a}$ & $79 / 84$ & $0.15^{a, f}$ & 473 & $(0.14,0.20)$ & 24.1 & [54] \\
\hline B4 & $-/-$ & $481^{a}$ & $89 / 91$ & $0.082^{a, f}$ & 480 & $(0.14,0.34)$ & 26.1 & [54] \\
\hline B5 & $-/-$ & $453^{a}$ & $69 / 83$ & $0.15^{a, f}$ & 455 & $(0.14,0.10)$ & 16.1 & [54] \\
\hline B6 & $-/-$ & $458^{a}$ & $42 / 63$ & $0.16^{a, f}$ & 449 & $(0.15,0.06)$ & 14.9 & [54] \\
\hline B7 & $-/ 419$ & $452^{b}$ & $-/ 99^{e}$ & $0.31^{b, f}$ & 454 & $(0.14,0.10)$ & 5.5 & [55] \\
\hline B8 & $-/ 446$ & $458^{b}$ & $-/ 98^{e}$ & $0.30^{b, f}$ & - & - & - & [55] \\
\hline B9 & $-/ 456$ & $451^{b}$ & $-/ 56^{e}$ & $0.26^{b, f}$ & 464 & $(0.14,0.15)$ & 12.4 & {$[55]$} \\
\hline B10 & $-/ 414$ & $469^{b}$ & $-/ 95^{e}$ & $0.11^{b, f}$ & 469 & $(0.14,0.19)$ & 20.8 & [55] \\
\hline B11 & $-/ 421$ & $512^{b}$ & $-/ 99^{e}$ & $0.04^{a, f}$ & 512 & $(0.26,0.57)$ & 27.5 & [55] \\
\hline T1 & $-/-$ & $458^{a}$ & $54 / 74$ & $0.09^{a, f}$ & 487 & $(0.19,0.35)$ & 20.6 & [57] \\
\hline $\mathbf{T} 2$ & $-/-$ & $451^{a}$ & $74 / 80$ & $0.28^{a, f}$ & 478 & $(0.17,0.27)$ & 16.8 & [57] \\
\hline T3 & $-/-$ & - & $43 /-$ & $0.23^{a, f}$ & 459 & $(0.15,0.16)$ & 17.8 & [58] \\
\hline T4 & $-/-$ & - & $99 / 100$ & $0.07^{a, f}$ & 500 & $(0.25,0.50)$ & 25.5 & [58] \\
\hline T5 & $-/-$ & - & $84 / 98$ & $0.20^{a, f}$ & 496 & $(0.23,0.46)$ & 21.3 & {$[58]$} \\
\hline T6 & $125 / 366$ & - & $16.7 /-$ & 0.1 & 470 & $(0.15,0.22)$ & 9.3 & [59] \\
\hline $\mathbf{T 7}$ & $124 / 309$ & - & $50.5 /-$ & 0.03 & 484 & $(0.17,0.34)$ & 14.7 & [59] \\
\hline T8 & $128 / 373$ & - & $43.0 /-$ & 0.01 & 480 & $(0.17,0.31)$ & 12.3 & [59] \\
\hline T9 & $-/ 366$ & $418^{a}$ & $74 / 54$ & $0.30^{a, f}$ & $437^{i}$ & $(0.15,0.09)^{i}$ & 5.4 & {$[60]$} \\
\hline T10 & $-/ 546$ & $429^{a}$ & $73 / 88$ & $0.21^{a, f}$ & $445^{i}$ & $(0.15,0.10)^{i}$ & 15.5 & {$[60]$} \\
\hline T11 & $90 / 334$ & $495^{b}$ & $-/ 59$ & $0.062^{b_{i} f}$ & - & $(0.21,0.50)$ & 27.4 & [62] \\
\hline T12 & $136 / 368$ & $478^{b}$ & $-/ 82$ & $0.133^{b, f}$ & - & $(0.17,0.38)$ & 25.8 & [62] \\
\hline T13 & $155 / 353$ & $480^{b}$ & -100 & $0.072^{b_{f} f}$ & - & $(0.18,0.43)$ & 36.7 & [62] \\
\hline T14 & $-/-$ & - & $-/ 97.9$ & $0.002^{b_{i} f}$ & 477 & $(0.18,0.31)$ & 20.4 & [63] \\
\hline T15 & $-/-$ & - & $-/ 31.1$ & $0.191^{b f f}$ & 473 & $(0.17,0.25)$ & 13.2 & [63] \\
\hline T16 & $-/-$ & - & $-/ 85.3$ & $0.302^{b, f}$ & 465 & $(0.15,0.18)$ & 16.7 & [63] \\
\hline T17 & $-/ 393$ & $420^{a}$ & $-/ 58$ & $0.22^{a, f}$ & $436^{i}$ & $(0.16,0.11)^{i}$ & 4.5 & [65] \\
\hline T18 & $181 / 493$ & $454^{a}$ & $-/ 45$ & $0.35^{a, f}$ & $452^{i}$ & $(0.15,0.13)^{i}$ & 5.4 & [64] \\
\hline T19 & $197 / 481$ & $444^{a}$ & $-/ 51$ & $0.24^{a, f}$ & $456^{i}$ & $(0.16,0.17)^{i}$ & 7.21 & [64] \\
\hline $\mathbf{T 2 0}$ & $208 / 447$ & $448^{a}$ & $-/ 84$ & $0.43^{a}$ & $484^{i}$ & $(0.20,0.33)^{i}$ & 18.7 & [65] \\
\hline T21 & $178 / 428$ & $432^{a}$ & $-/ 85.6^{e}$ & $0.19^{b, f}$ & 468 & $(0.15,0.18)$ & 17.2 & {$[67]$} \\
\hline T22 & $-/ 463$ & $442^{a}$ & $-/ 91.1^{e}$ & $0.17^{b, f}$ & 472 & $(0.15,0.22)$ & 17.9 & [67] \\
\hline T23 & $170 / 374$ & $456^{a}$ & $-/ 93.3^{e}$ & $0.15^{b, f}$ & 480 & $(0.16,0.30)$ & 22.8 & [67] \\
\hline T24 & $181 / 436$ & $446^{a}$ & $-/ 97.9^{e}$ & $0.11^{b, f}$ & 472 & $(0.15,0.24)$ & 25.9 & {$[67]$} \\
\hline T25 & $-/-$ & $432^{a}$ & $72 / 87$ & $0.43^{a, f}$ & - & - & 7.2 & [52] \\
\hline T26 & $-/-$ & $465^{a}$ & $86 / 98$ & $0.08^{a, f}$ & - & - & 22 & [52] \\
\hline T27 & $-/-$ & $432^{a}$ & $60 / 92$ & $0.17^{a, f}$ & - & $(0.15,0.10)$ & 19.2 & [52] \\
\hline T28 & $-/-$ & $432^{a}$ & $35 / 85$ & $0.15^{a, f}$ & - & $(0.15,0.10)$ & 18.3 & {$[52]$} \\
\hline T29 & $-/ 381$ & $473^{a}$ & $-/ 100$ & $0.24^{a, f}$ & - & $(0.27,0.57)$ & 21.32 & [68] \\
\hline T30 & $97 / 351$ & $457^{a}$ & $-/ 100$ & $0.27^{a, f}$ & - & $(0.21,0.47)$ & 21.21 & [68] \\
\hline T31 & $-/ 358$ & $424^{a}$ & $-/ 19$ & $0.45^{a, f}$ & - & $(0.22,0.45)$ & 13.52 & [68] \\
\hline T32 & $-/-$ & $468^{b}$ & $-/ 70$ & $0.16^{b, f}$ & - & $(0.15,0.20)$ & 22.3 & [69] \\
\hline T33 & $-/-$ & $465^{b}$ & $-/ 64$ & $0.16^{b, f}$ & 464 & $(0.15,0.16)$ & 23.7 & [69] \\
\hline T34 & $-/-$ & $458^{b}$ & $-/ 43$ & $0.18^{b, f}$ & 456 & $(0.15,0.13)$ & 16 & [69] \\
\hline T35 & $-/-$ & $472^{a}$ & $-/ 17$ & $0.18^{a, f}$ & 487 & $(0.18,0.25)$ & 6.8 & {$[70]$} \\
\hline T36 & $-/-$ & $478^{a}$ & $-/ 68$ & $0.093^{a, f}$ & 496 & $(0.22,0.39)$ & 12.3 & [70] \\
\hline
\end{tabular}




\begin{tabular}{|c|c|c|c|c|c|c|c|c|}
\hline Emitter & $\begin{array}{l}T_{\mathrm{g}} / T_{\mathrm{d}} \\
/{ }^{\circ} \mathrm{C} \\
\end{array}$ & $\lambda_{\mathrm{PL}} / \mathrm{nm}$ & $\begin{array}{l}\mathrm{PLQY}^{d} / \% \\
\text { (Sol./film) }\end{array}$ & $\Delta E_{\mathrm{ST}} / \mathrm{eV}$ & $\lambda_{\mathrm{EL}} / \mathrm{nm}$ & CIE & $\mathrm{EQE} / \%$ & Ref. \\
\hline T37 & $-/-$ & $472^{a}$ & $\begin{array}{l}/ 98 \\
\end{array}$ & $0.077^{a, f}$ & 496 & $(0.21,0.44)$ & 28.3 & [70] \\
\hline T38 & $-/-$ & $456^{a}$ & $-/ 37$ & $0^{a, f}$ & 484 & $(0.20,0.30)$ & 16.4 & [70] \\
\hline T39 & $150 / 470$ & - & $-/ 84$ & $0.24^{a, f}$ & 482 & $(0.17,0.28)$ & 24.8 & [71] \\
\hline T40 & $158 / 474.4$ & - & $-/ 87$ & $0.16^{a, f}$ & 482 & $(0.17,0.30)$ & 26.7 & [71] \\
\hline T41 & $-/ 461.2$ & - & $-/ 90$ & $0.11^{a, f}$ & 488 & $(0.18,0.35)$ & 28.5 & [71] \\
\hline S1 & $-/-$ & $402^{a}$ & $57 / 60$ & 0.54 & - & - & 2.9 & [42] \\
\hline S2 & $-/-$ & $419^{a}$ & $65 / 66$ & 0.45 & - & - & 5.6 & [42] \\
\hline S3 & $-/-$ & - & $-/ 70$ & 0.18 & - & $(0.23,0.39)$ & 18.02 & [73] \\
\hline S4 & $-/-$ & - & $-/ 92$ & 0.05 & - & $(0.29,0.52)$ & 14.84 & [73] \\
\hline S5 & $-/-$ & $451^{a}$ & 64/- & - & - & - & - & [74] \\
\hline S6 & $-/-$ & $450^{a}$ & $79 / 80$ & $0.42^{a, f}$ & 435 & $(0.16,0.08)$ & 8.5 & [74] \\
\hline S7 & $-/-$ & $444^{a}$ & $82 / 81$ & $0.47^{a, f}$ & 456 & $(0.17,0.18)$ & 5.3 & [74] \\
\hline S8 & $-/-$ & $454^{a}$ & $80 / 82$ & $0.43^{a, f}$ & 458 & $(0.17,0.19)$ & 5 & [74] \\
\hline S9 & $-/ 362$ & $424^{a}$ & $-/ 6$ & $0.20^{b, f}$ & - & - & - & [46] \\
\hline S10 & $-/ 399$ & $437^{a}$ & $-/ 54$ & $0.09^{b, f}$ & 455 & $(0.13,0.13)$ & 10.5 & [46] \\
\hline S11 & $-/ 386$ & $488^{a}$ & $-/ 48$ & $0.24^{b, f}$ & - & - & - & [46] \\
\hline S12 & $171 / 339$ & $461^{a}$ & $-/ 77.5$ & $0.03^{b, f}$ & 456 & $(0.15,0.16)$ & 17.0 & [75] \\
\hline S13 & $-/ 391$ & $461^{a}$ & $-/ 81.0$ & $0.03^{b, f}$ & 456 & $(0.15,0.19)$ & 24.1 & [75] \\
\hline S14 & $-/ 361$ & $462^{a}$ & $-/ 81.2$ & $0.02^{b, f}$ & 457 & $(0.15,0.17)$ & 20.1 & [75] \\
\hline S15 & $98 / 349$ & $462^{a}$ & $-/ 84.7$ & $0.11^{b, f}$ & 458 & $(0.16,0.21)$ & 14.6 & [75] \\
\hline S16 & $74 / 366$ & $462^{a}$ & $-/ 75.5$ & $0.07^{b, f}$ & 457 & $(0.16,0.20)$ & 12.6 & [75] \\
\hline S17 & $-/-$ & $506^{a}$ & $-/ 80$ & $0.06^{b . f}$ & - & $(0.16,0.25)$ & 21.2 & [76] \\
\hline S18 & $-/-$ & $495^{a}$ & $-/ 88$ & $0.05^{b, f}$ & - & $(0.15,0.18)$ & 22.6 & [76] \\
\hline N1 & $-/ 430$ & $489^{a}$ & $-/ 77$ & $0.18^{b, f}$ & 499 & $(0.21,0.44)$ & 20.9 & [79] \\
\hline N2 & $-/ 442$ & $484^{a}$ & $-/ 79$ & $0.19^{b, f}$ & 498 & $(0.21,0.44)$ & 19 & [79] \\
\hline N3 & $-/ 432$ & $478^{a}$ & $-/ 80$ & $0.19^{b, f}$ & 489 & $(0.19,0.37)$ & 20.4 & [79] \\
\hline N4 & $-/ 518$ & $469^{a}$ & $-/ 96.6^{e}$ & $0.15^{a, f}$ & 487 & $(0.18,0.34)$ & 25.56 & [80] \\
\hline N5 & $-/ 487$ & $460^{a}$ & $-/ 82.2^{e}$ & $0.19^{a, f}$ & 479 & $(0.17,0.29)$ & 24.36 & [80] \\
\hline N6 & $-/ 535$ & $464^{a}$ & $-/ 97.0^{e}$ & $0.16^{a, f}$ & 484 & $(0.18,0.32)$ & 31.45 & [80] \\
\hline N7 & $-/ 422$ & $458^{a}$ & $-/ 87^{e}$ & $0.25^{b_{i} f}$ & 470 & $(0.16,0.23)$ & 20.4 & [81] \\
\hline N8 & $-/ 351$ & $461^{a}$ & $-/ 91^{e}$ & $0.26^{b, f}$ & 469 & $(0.16,0.21)$ & 17.1 & [81] \\
\hline N9 & $-/ 422$ & $451^{a}$ & $-/ 69^{e}$ & $0.25^{b, f}$ & 462 & $(0.16,0.20)$ & 12.2 & [81] \\
\hline N10 & $-/ 354$ & $454^{a}$ & $-/ 90^{e}$ & $0.29^{b, f}$ & 460 & $(0.16,0.19)$ & 14.3 & [81] \\
\hline N11 & $-/ 423$ & $477^{a}$ & $-/ 75$ & $0.23^{c, f}$ & 477 & $(0.17,0.28)$ & 24 & [82] \\
\hline N12 & $-/ 421$ & $477^{a}$ & $-/ 71$ & $0.22^{c, f}$ & 477 & $(0.17,0.27)$ & 19.8 & [82] \\
\hline N13 & $-/ 414$ & $454^{a}$ & $-/ 47$ & $0.24^{c, f}$ & 451 & $(0.16,0.15)$ & 17.8 & [82] \\
\hline N14 & $-/-$ & $484^{a}$ & $28.1 / 76.0^{e}$ & 0.31 & 480 & $(0.16,0.30)$ & 14 & [85] \\
\hline N15 & $-/-$ & $453^{a}$ & $28.7 / 46.4^{e}$ & 0.36 & 446 & $(0.16,0.12)$ & 4.7 & [85] \\
\hline N16 & $-/-$ & $466^{a}$ & $38.3 / 62.0^{e}$ & 0.35 & 4.55 & $(0.16,0.15)$ & 6.8 & [85] \\
\hline N17 & $-/-$ & $487^{a}$ & $39.1 / 74.9^{e}$ & 0.29 & 474 & $(0.16,0.25)$ & 11.2 & [85] \\
\hline N18 & $-/-$ & $459^{a}$ & $47 / 41.1^{e}$ & 0.41 & 446 & $(0.15,0.11)$ & 6.6 & [85] \\
\hline 01 & $-/ 370$ & $440^{a}$ & $1 / 38$ & $0.29^{a, f}$ & $452^{i}$ & $(0.16,0.13)^{i}$ & 4.2 & [86] \\
\hline $\mathrm{O} 2$ & $86 / 382$ & $467^{a}$ & $18 / 70$ & $0.13^{a, f}$ & $476^{i}$ & $(0.17,0.27)^{i}$ & 9.4 & [86] \\
\hline $\mathbf{O 3}$ & $108 / 399$ & $480^{a}$ & $17.8 / 72$ & $0.07^{a, f}$ & $477^{i}$ & $(0.18,0.28)^{i}$ & 11 & [86] \\
\hline 04 & $106 / 530$ & $482^{a}$ & $24.3 / 96$ & $0.05^{a, f}$ & $485^{i}$ & $(0.19,0.32)^{i}$ & 23.9 & [86] \\
\hline 05 & $109 / 382$ & $490^{a}$ & $14 / 88.0$ & $0.03^{a, f}$ & 488 & $(0.17,0.36)$ & 24 & [87] \\
\hline 06 & $140 / 412$ & $508^{a}$ & $36 / 91.4$ & $0.04^{a, f}$ & 514 & $(0.30,0.64)$ & 27.2 & [87] \\
\hline 07 & $-/ 448$ & - & $-/ 46$ & $0.27^{b, f}$ & 449 & $(0.15,0.08)$ & 12.4 & [88] \\
\hline 08 & $82 / 450$ & - & $-/ 50$ & $0.19^{b, f}$ & 456 & $(0.14,0.13)$ & 16 & [88] \\
\hline O9 & $-/ 401$ & $477^{c}$ & $-/ 54.6$ & $0.18^{c, f}$ & $462^{h}$ & $(0.15,0.17)^{h}$ & 15.3 & [89] \\
\hline 010 & $-/ 444$ & $490^{c}$ & $-/ 67.5$ & $0.14^{c, f}$ & $470^{h}$ & $(0.15,0.22)^{h}$ & 20.9 & [89] \\
\hline
\end{tabular}

${ }^{a}$ Dispersed in solution; ${ }^{b}$ dispersed in a host film; ${ }^{c}$ neat film; ${ }^{d}$ under $\mathrm{N}_{2}$ conditions $;{ }^{e}$ absolute PLQY from integrating sphere measurement; ${ }^{f}$ calculated from the PL measurement; ${ }^{g}$ non-doped devices; ${ }^{h, i}$ EL wavelength, CIE coordinates at a driving voltage of $6 \mathrm{~V}, 8 \mathrm{~V}$.

\section{1 氭基类}

由于具有较强的吸电子能力和直线构型, 作为电子 受体的氰基通常以芳族化合物氧基取代的形式广泛应 用于构建小 $\Delta E_{\mathrm{ST}}$ 、高苂光辐射衰减率 $\left(k_{\mathrm{r}}\right)$ 的 D-A 型 TADF 分子. 2012 年, Adachi 等 ${ }^{[47]}$ 报道了第一例基于咔唑和苯 二腈基团的纯有机蓝光 TADF 分子. 2015 年 Shim、Yang 和 Lee 团队 ${ }^{[48]}$ 联合报道了两种二氰基苯基衍生物 C1 和
C2(图 3)，并比较了叔丁基引入前后对分子物化特性和 发光器件性能的影响. 研究结果发现叔丁基的引入会降 低分子的 PLQY, 并造成发射光谱较大的红移. 在 $\mathrm{TADF}$ 材料掺杂浓度为质量分数 $10 \%, 2,8$-二(二苯基氧 膦基)二苯并噻吩(PPT)为主体材料的 OLED 器件中, 含 有叔丁基的 $\mathbf{C 2}$ 对应最大电流效率 $\left(\mathrm{CE}_{\max }\right)$ 为 $4.70 \mathrm{~cd}$ ・ $\mathrm{A}^{-1}$, 最大亮度 $\left(L_{\max }\right)$ 为 $470.28 \mathrm{~cd} \cdot \mathrm{m}^{-2}$, 最大 $\mathrm{EQE}$ 为 
$5.05 \%$, 相较 C1 的器件性能都有所提升, 但 CIE 色坐标 偏移较为明显.

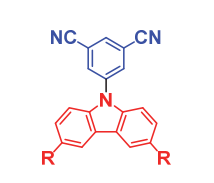

$C 1: R=H$

$\mathrm{C} 2: \mathrm{R}=\mathrm{Bu}$

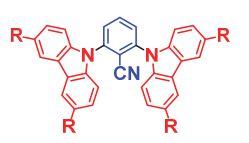

C7: $\mathbf{R}=\mathbf{H}$

$\mathrm{C8}: \mathrm{R}=\mathrm{Me}$

C9: $R=B u$

C10: $R=O M e$

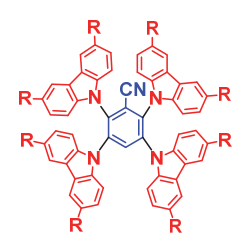

C3: $\mathbf{R}=\mathbf{H}$

C4: $R=B u$

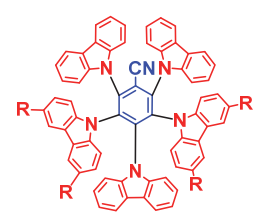

\section{C11: $R=M e$}

C12: $R=P h$

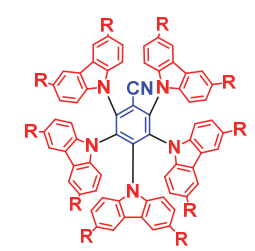

C5: $\mathbf{R}=\mathbf{H}$

$\mathrm{C} 6: \mathrm{R}=\mathrm{Bu}$

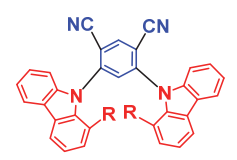

C13: $R=H$ $\mathrm{C} 14: \mathrm{R}=\mathrm{Me}$
图 3 含氧基受体的 TADF 分子

Figure 3 TADF molecules with cyano-containing acceptor

为了有效提高 OLED 器件的使用寿命, 随后 Duan 研究组 ${ }^{[49]}$ 构建了具有多数量并修饰的咔唑给体, 苯基 和氰基分别作为桥连基团和受体单元的咔唑基蓝光 $\mathrm{TADF}$ 分子 $\mathbf{C 3} \sim \mathbf{C 6}$ (图 3), 考察了电子给体咔唑的数量 及叔丁基取代基对 TADF-OLED 的器件性能和寿命的影 响. 研究发现在外围咔唑单元上接入叔丁基能够起到增 加溶解度、屏蔽发光核、阻断咔唑的活性位点和提高分 子稳定性的作用, 咔唑单元的增加会形成离域电荷转移 三线态 $\left({ }^{3} \mathrm{CT}\right)$, 使得三线态更稳定, 并且增加的空间拥挤 度和构象变化的阻碍也增强了其稳定性. 咔唑和叔丁基 的引入同时都会使得分子的 HOMO 能级下移, $\Delta E_{\mathrm{ST}}$ 减 小, 并且使得 PLQY 和延迟组分的量子效率都有明显的 提高. 其中 C6 化合物的 PLQY 达 $86 \%$, 延迟组分的量 子效率达 73\%. 以 3, $3^{\prime}$-二( $N$-咔唑基)-1, $1^{\prime}$-联苯(mCBP)为 主体, 发光分子掺杂浓度为质量分数 $40 \%$ 制备的 OLED 器件表现出天蓝光发射. 对比器件性能可以发现, 咔唑 单元数的增加和叔丁基的引入可以显著提高 $\mathrm{EQE}$ 、功率 效率(PE)和器件寿命等, 其中基于化合物 C6 的 OLED 的 $\mathrm{EQE}_{\max }$ 为 $21.2 \%$ 、最大的功率效率 $\left(\mathrm{PE}_{\max }\right)$ 为 56.1 $\mathrm{lm} \cdot \mathrm{W}^{-1}$ 、 LT50 (达到初始亮度的 50\%的时间)为 $770 \mathrm{~h}$ (初 始亮度 $\left.L_{0}=500 \mathrm{~cd} \cdot \mathrm{m}^{-2}\right), \mathrm{CIE}$ 色坐标为 $(0.21,0.41)$. 需要 指出的是咔唑基团的增加和叔丁基的引入都会导致 CIE 色坐标产生一定的偏移, 其中咔唑基团影响更大, 尤其 是对于 $y$ 值.

在高效深蓝光器件的探索中, 2018 年 Adachi 等 ${ }^{[50]}$ 结合了咔唑给体和芐腈受体, 引入甲基、叔丁基和甲氧 基等来调节给体的给电子能力, 成功开发出 4 种深蓝光 TADF 分子 $\mathbf{C 7} \sim \mathbf{C 1 0}$ (图 3). TDDFT 量子化学计算表明 四个化合物 D-A 的二面角都在 $66^{\circ}$ 左右, 具有 $0.13 \mathrm{eV}$ 的 $\Delta E_{\mathrm{ST}}$ 和较高的 PLQY. 作者发现三种取代基均能提高
咔坐基给体的给电子能力，显著降低目标分子的 $\Delta E_{\mathrm{ST}}$, 增强其 TADF 特性和提高薄膜的 PLQY, 且取代基效应 的趋势为甲氧基 $>$ 叔丁基 $>$ 甲基. 其中含有甲氧基的分 子 $\mathrm{C10}$ 表现出最小的 $\Delta E_{\mathrm{ST}}$ 和最高的 PLQY, 分别为 0.14 $\mathrm{eV}$ 和 $86 \%$. 采用氧化二[2-(二苯基膦基)苯基]醚 (DPEPO):TADF 材料 $(w=10 \%)$ 的掺杂型发光层(EML)制 备了 OLED 器件, 基于 $\mathbf{C 8}$ 和 C9 的 TADF-OLED 器件, 既保持了深蓝光发射( $y$ 坐标低于 0.07 ), 同时得到了高 于 $10 \%$ 的 $\mathrm{EQE}$. 其中甲氧基的给电子能力最强, 器件发 射红移最大, CIE 的 $y$ 值从 $<0.07$ 偏移到 $>0.20$.

同年, 受 Duan 研究组 ${ }^{[49]}$ 工作启发, Adachi 团队 [51] 以 $\mathrm{C5}$ 为母体分子，在咔唑单元上引入甲基和苯基合成 了 C11 和 $\mathrm{C12}$ 两种新型 TADF 分子(图 3). 通过在咔唑 的 3,6 位引入取代基构建了第二给体, 既保留了原来体 系的 CT 特性, 同时又降低分子的 ${ }^{3} \mathrm{LE}$ 能级, 从而促进 了高效 RISC 过程. 此外, 甲基与苯基会降低分子的对 称性, 提高发光材料的溶解性, 有利于实现全溶液加工 型 OLED 器件. 两种取代基的引入均会使得 PL 光谱发 生轻微红移, 但间位取代对体系的供电子能力影响较 小, 使得材料的 $\Delta E_{\mathrm{ST}}$ 变化非常小. $\mathrm{C} 11$ 和 $\mathrm{C} 12$ 分子都表 现出较高的 PLQY, 分别为 $85 \%$ 和 $81 \%$, 同时获得了 $2.99 \mathrm{eV}$ 和 $2.87 \mathrm{eV}$ 的 ${ }^{3} \mathrm{LE}$ 态, 实现了 $\mathrm{LE}$ 与 $\mathrm{CT}$ 特性之 间的混合, 其 $K_{\mathrm{RISC}}$ 分别达 $4.4 \times 10^{5} \mathrm{~s}^{-1}$ 和 $7.2 \times 10^{5} \mathrm{~s}^{-1}$. 以 $\mathrm{mCBP}$ 为主体材料, 化合物 C11、C12 掺杂浓度为质 量分数 $20 \%$ 制备的 OLED 器件表现出蓝绿光发射. 对比 发现, 基于 $\mathrm{C12}$ 的器件 $\mathrm{EQE}$ 提升较小, 但效率滚降得到 明显改善, 器件的工作寿命显著提高, 在 $L_{0}=1000$ $\mathrm{cd} \cdot \mathrm{m}^{-2}$ 情况下, LT97(达到初始亮度的 $97 \%$ 的时间)达到 了 $110 \mathrm{~h}$, 其原因在于引入的苯基改善了载流子传输特 性并引起了载流子复合区域位置和宽窄的变化.

为解决蓝光 TADF 分子常见的 RISC 速率慢、器件 效率下降等问题. 最近, Kazlauskas 等 ${ }^{[52]}$ 利用 1 号位甲基 化的咔唑与间苯二腈受体合成两种蓝光分子 C13 和 C14. 理论计算结果表明 D-A 的二面角从 $52^{\circ}$ 增大到 $70^{\circ}$, $\mathrm{CT}$ 特性明显增强. 咔唑甲基化会导致 PL 光谱红移 17 $\mathrm{nm}$, 延迟寿命 $\tau_{\mathrm{d}}$ 显著的降低(从 $29.4 \mu \mathrm{s}$ 缩短到 $1.71 \mu \mathrm{s}$ ), 薄膜的 PLQY 提升了 $23 \%$ (达到了 $74 \%$ ). $K_{\mathrm{RISC}}$ 提升显著, 提升了 35 倍, 为 $2.47 \times 10^{6} \mathrm{~s}^{-1} . \mathrm{C14}$ 分子具有高的 RISC 速率和短的延迟寿命, 有利于器件性能的提升. 以 $1,3-$ 二 (9 氢-咔唑-9-基)苯(mCP)为主体材料，化合物 C13、C14 掺杂浓度为质量分数 7\%制备 EML 层, 利用溶液加工技 术和真空沉积技术制备两种蓝光器件. 在溶液加工的器 件中, 基于 C14 的器件最大 $\mathrm{EQE}$ 达到 $21.6 \%$, 效率滚降 明显改善. 在溶液加工的蓝/天蓝光器件中这两个性能 表现最优. 真空沉积型的器件性能优于溶液加工型的, C14 器件性能最优, $\mathrm{EQE}_{\max }$ 为 $23.8 \%, L_{\max }$ 为 $95743 \mathrm{~cd}$ • $\mathrm{m}^{-2}, \mathrm{CIE}$ 坐标为 $(0.16,0.28)$. 


\section{2 硼类}

嗍原子常被用于构建三芳基嗍单元, 使其具有较大 的空间体积, 易保持扭曲的 D-A 结构, 可作为蓝光 TADF 材料的电子受体. 2018 年 $\mathrm{Lu}$ 等 ${ }^{[53]}$ 利用空间电荷转 移策略开发了两种含有三芳基硼受体和咔唑给体的高 效蓝光 TADF 分子 B1 和 B2 (图 4). 通过 DFT 和 TDDFT 进行优化及计算, 结果表明两个分子的 D-A 单元呈近似 平行的状态，预测分子不仅具有 ICT 特性，还具有空间 电荷转移(TSCT)特性. 两种分子高度扭曲的非平面结 构和烷基取代基的存在使得分子发光的自猝灭效应得 到了有效的抑制. 同时, B2 分子中额外的两个叔丁基又 进一步降低了分子间的 $\pi-\pi$ 堆积, 进而抑制了三线态-三 线态激子猝灭(TTA). 与 $\mathbf{B} 1$ 相比, 含有叔丁基的 B2 具 有更高的 PLQY (94\%), 更短的延迟寿命 $\left(\tau_{\mathrm{d}}=14 \mu \mathrm{s}\right)$ 和更 窄的半峰宽 $(F W H M=56 \mathrm{~nm})$. 相同条件下, 利用 B1 和 B2 制备的非掺杂型溶液法加工蓝光 OLED 器件的 $\mathrm{EQE}_{\text {max }}$ 分别为 $8.0 \%$ 和 $19.1 \%$, CIE 色坐标分别为 $(0.15$, $0.17)$ 和 $(0.15,0.26)$. 在 $1000 \mathrm{~cd} \cdot \mathrm{m}^{-2}$ 的亮度下, 基于 $\mathbf{B} 2$ 的 TADF-OLED 的 EQE 仍能保持在 9.7\%.

随后 Lee 和 Yoo 团队 ${ }^{[54]}$ 利用相似的结构合成了化合 物 $\mathbf{B 3} \sim \mathbf{B}$ 6(图 4), 给体上引入叔丁基发现叔丁基会提高 HOMO 能级但对 LUMO 能级没有明显影响, 故 B4 的吸 收与发射光谱较 B3 均有一定红移. 此外, 与 $\mathbf{B 3}$ 相比, B4 表现出更高的 PLQY (89\%), 更小的 $\Delta E_{\mathrm{ST}}(0.17 \mathrm{eV})$ 和更短的 $\tau_{\mathrm{d}}(28.7 \mu \mathrm{s})$. 中心苯环引入甲基和甲氧基发现, 相比于甲基, 给电子能力更强的甲氧基会造更大的发射 蓝移, PLQY 降低也更明显, 降低了约 $40 \%$, 只表现出 $42 \%$ 的量子产率. 发现引入给体和桥连单元, 分子的性 能呈相反的趋势. 选取 DPEPO 为主体材料, TADF 材料 掺杂浓度为质量分数 $20 \%$ 制备了结构为 ITO $(150$ $\mathrm{nm}) / \mathrm{PEDOT}: \operatorname{PSS}(40 \mathrm{~nm}) / \mathrm{TAPC}(20 \mathrm{~nm}) / \mathrm{mCP}(10 \mathrm{~nm}) /$ DPEPO:emitter $(w=20 \%, 25 \mathrm{~nm}) / \mathrm{DPEPO}(10 \mathrm{~nm}) / \mathrm{TPBi}$ $(30 \mathrm{~nm}) / \mathrm{LiF}(1 \mathrm{~nm}) / \mathrm{Al}(100 \mathrm{~nm})$ 的蓝光 OLED 器件, B3 和 B4 表现出相近的 $\mathrm{EQE}_{\text {max }}$ 分别为 $24.1 \%$ 和 $26 \%$; 含有叔 丁基取代的 B4 的器件具有更小的效率滚降, 但其 CIE 色坐标 $y$ 值更大, 为 0.34. 而 B5、B6 表现出出色的色纯 度, CIE 色坐标为 $(0.141,0.099) 、(0.151,0.058)$, 但器件 性能下降明显, $\mathrm{B6}$ 器件的 $\mathrm{EQE}_{\max }$ 为 $17.3 \%$.

在有机嗍化合物中, 氮嗍烷的电子接受能力降低, 比三芳基嗍单元更具有适合蓝光发射的能级 ${ }^{[55]}$. Cheng 等 ${ }^{[55}$ 设计合成了 5 种以二苯并- 1,4 -氮硼烷为电子受体的 发光材料, 即化合物 B7 $\sim \mathbf{B 1 1}$ (图 4), 考察了不同结构的 芳香胺作为电子给体对化合物发光特性和器件性能的 影响, 发现电子给体及其取代基的不同对发光分子是否 具有 TADF 特性具有决定性影响. 他们研究发现咔唑和 3,6-二叔丁基咔唑为电子给体的化合物均具有较高的 PLQY, 但是给体与受体间的二面角较小, 因而没有明 显的 TADF 效应. 相反, 1,3,6,8-四甲基咔唑、9,9-二甲基
呋啶和噁噻嗪作为电子给体时, 产生了近乎垂直的二面 角，因此分子的 HOMO 和 LUMO 实现了有效的分离, 其 $\Delta E_{\mathrm{ST}}$ 最小为 $0.04 \mathrm{eV}$, 进而表现出 TADF 特性. 以上述 材料为发光客体, $\mathrm{mCP}$ 为主体材料, 掺杂浓度为质量分 数 $10 \%$, 制备得到了采用 ITO/NPB(20 nm)/TAPC(30 $\mathrm{nm}) / \mathrm{EML}(30 \mathrm{~nm}) / \mathrm{PPT}(10 \mathrm{~nm}) / \operatorname{TmPyPB}(70 \mathrm{~nm}) / \mathrm{LiF}(1$ $\mathrm{nm}) / \mathrm{Al}(100 \mathrm{~nm})$ 结构的发光器件. 发现以咔唑基衍生物 为电子给体的发光分子对应的器件均呈深蓝光发射, 无 取代基修饰的 B7 对应器件 $\mathrm{EQE}_{\text {max }}$ 只有 5.5\%, 含有四个 甲基取代的 $\mathbf{B 9}$ 取得了 $12.4 \%$ 的 $\mathrm{EQE}_{\max }$, 但在色纯度上 有一定损失, CIE 色坐标由原来的 $(0.14,0.10)$ 红移至 $(0.14,0.15)$. 而含有 9,9 -二甲基呋啶和噁噻嗪电子给体 的 B10 和 B11 由于存在更强的 ICT 作用，同样结构下制 备出的器件呈现出蓝光和绿光发射, 其 $\mathrm{EQE}_{\text {max }}$ 可达 $20.8 \%$ 和 $27.5 \%$.

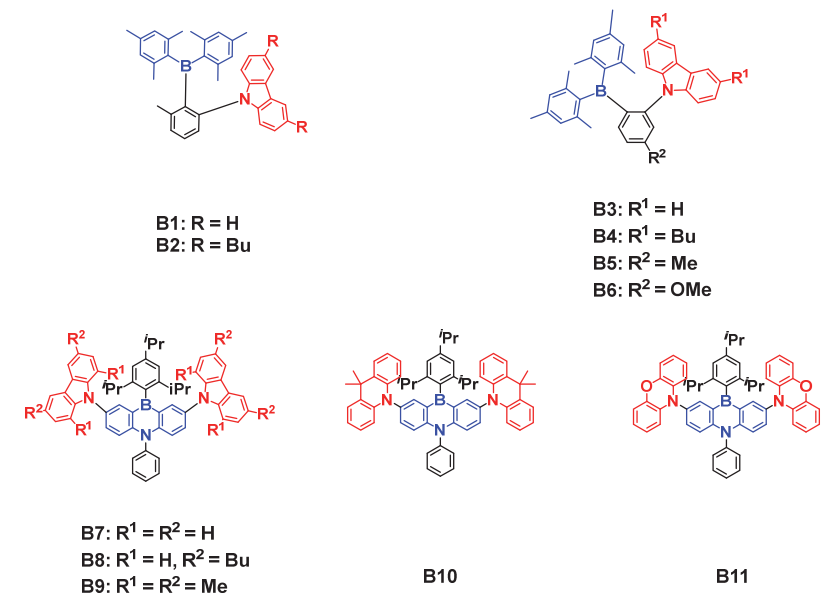

图 4 含嗍受体的 TADF 分子

Figure 4 TADF molecules with boron-containing acceptor

\section{3 三嗪类}

$1,3,5$-三嗪由于含有三个亚胺氮键, 呈现高度缺电 子特性, 并且环上有三个反应活性位点能进行不同化学 修饰，广泛应用于 D-A 型蓝光 TADF 材料的构筑 ${ }^{[56]}$. $\mathrm{TADF}$ 分子设计中最常用的是三嗪-咔唑体系和三嗪-呋 啶体系. 2015 年, Adachi 课题组 ${ }^{[57]}$ 设计了以 2,4,6-三苯 基-1,3,5-三嗪为电子受体, 咔唑衍生物为电子给体的蓝 光 TADF 分子 T1 和 T2(图 5), 考察了苯基取代基对发光 分子物化性质及其 OLED 的器件性能和寿命的影响. 作 者发现叔丁基的引入增加了咔唑基电子给体与三嗪受 体间的空间位阻，使得 HOMO 和 LUMO 能级分离程度 更显著, 因而 $\mathbf{T} 2$ 表现出比 T1 更小的 $\Delta E_{\mathrm{ST}}(0.09 \mathrm{eV})$ 和 更大的振子强度 $f$, 更快的苂光辐射衰减率 $K_{\mathrm{r}}$ 和更高的 PLQY. 在 ITO/mCBP(10 nm)/DPEPO:guest $(w=6 \%, 15$ $\mathrm{nm}) / \mathrm{DPEPO}(10 \mathrm{~nm}) / \mathrm{TPBi}(30 \mathrm{~nm}) / \mathrm{LiF}(0.8 \mathrm{~nm}) / \mathrm{Al}$ 的器件 结构中, $\mathbf{T} 2$ 对应的最大外部量子效率达 $20.6 \%, \mathrm{~T} 1$ 为 $16.8 \%$; 但其在色纯度上有一定的损失, CIE 从 $(0.17$, $0.27)$ 偏移至 $(0.19,0.35)$. 
为了考察引入甲基的数量及其分布对发光分子性 质和器件性能的影响, Lee 等 ${ }^{[58]}$ 合成了三种 $1,3,5$-三嗪类 $\mathrm{TADF}$ 分子 $\mathbf{T 3} \sim \mathbf{T 5}$ (图 5). 在理论计算中 $\mathbf{T 3} 、 \mathbf{T 4}$ 的 HOMO 能级均匀分布, 而 $\mathbf{T 5}$ 的 HOMO 能级分布不均 匀. 实验证明 $\mathrm{HOMO}$ 能级在给体单元上均匀分布的重 要性, 其中化合物 $\mathbf{T 4}$ 的 HOMO 能级均匀分布, $\Delta E_{\mathrm{ST}}$ 降 低明显, 表现出高达 99\%的 PLQY. 而化合物 T5 的 $\mathrm{HOMO}$ 能级分布不均匀, $\Delta E_{\mathrm{ST}}$ 增大, PLQY 降低. 以 DPEPO:TADF 分子 $(w=30 \%)$ 为发光层制备的 OLED 器 件, 发现甲基分布均匀的器件性能得到较大的提升. 基 于化合物 $\mathbf{T} 4$ 的 OLED 器件 $\mathrm{EQE}_{\max }$ 为 $25.5 \%, \mathrm{PE}_{\max }$ 为 $52.1 \mathrm{~lm} \cdot \mathrm{W}^{-1}$. 但需要指出的是甲基会严重损害器件的 色纯度, 由蓝光发射转变为绿光发射.

三嗪与咔唑体系常见的构建方式为对位与间位连 接, 以邻位连接的化合物相对较少. 2016 年, Gong 等 ${ }^{[59]}$ 以不同烷基修饰的咔唑基团为电子给体、1,3-二苯基三 嗪为电子受体, 以邻位的方式与桥连苯基相连合成了化 合物 T6 T8 三种 TADF 蓝光分子(图 5). 与 T6 相比, 烷 基修饰的 T7 和 T8 具有更强的给电子能力, 表现出更强 的 ICT, 从而发射光谱产生相应的红移. 同时, T7 和 T8 表现出更低的 $\mathrm{S}_{1}$ 能级和更小的 $\Delta E_{\mathrm{ST}}(0.01 \mathrm{eV})$, 进而有 利于实现高效的 RISC 并获得较高的 PLQY 值 $(50.5 \%$ 和 43.0\%). 叔丁基提高材料热稳定性, 而甲基表现出相 反的作用. 以 $\mathrm{mCP}: \mathrm{TADF}$ 分子 $(w=5 \%)$ 制备了 OLED 器 件, 发现甲基和叔丁基的引入能显著提高 $\mathrm{EQE}$ 和 $\mathrm{CE}$ 等 器件性能, 归因于 $\mathbf{T} 7$ 和 $\mathbf{T 8}$ 具有更高的 PLQY. 与叔丁 基相比, 甲基的提升效果更好. 化合物 $\mathbf{T} 7$ 对应的器件 $\mathrm{EQE}_{\max }$ 为 $14.7 \% 、 \mathrm{CE}_{\max }$ 为 $30.92 \mathrm{~cd} \cdot \mathrm{A}^{-1}$, 但需要指出的 是其 CIE 色坐标 $y$ 值与基于 $\mathbf{T} 6$ 的器件的色坐标有较大 的偏移.

近来，笔者课题组 ${ }^{[60]}$ 通过简单的 Friedel-Crafts 反 应, 将 9-苯基芴引入咔唑单元合成了深蓝光 TADF 分子 $\mathbf{T 1 0}$ (图 5). 具有较大空间位阻的 9-苯基芴基的引入使得 咔唑与桥连苯基之间的二面角增加了近 40 , 获得了近 乎垂直 $\left(89.6^{\circ}\right)$ 的分子构型, 从而有效分离 $\mathrm{HOMO}$ 与 LUMO 能级, 实现了较小的 $\Delta E_{\mathrm{ST}}$, 进而有效促进了 RISC 过程. 此外, 与化合物 T9 相比, 化合物 T10 表现 出优良的热与电化学稳定性, 其热分解温度 $T_{\mathrm{d}}$ 高达 $546{ }^{\circ} \mathrm{C}$, 循环伏安法 $(\mathrm{CV})$ 多圈扫描后曲线几乎没有变 化. 同上述甲基和叔丁基类似，9-苯基芴的引入能够有 效增强咔唑的供电子能力, 使得吸收光谱和发射光谱红 移约 $11 \mathrm{~nm}$. 以这两种 TADF 分子为发光客体制备得到 了深蓝光器件, T9 和 T10 对应的发射峰波长分别 437 $\mathrm{nm}$ 和 $445 \mathrm{~nm}, \mathrm{CIE}$ 坐标分别为 $(0.15,0.09)$ 和(0.15, 0.10). 与基于 $\mathbf{T 9}$ 的器件相比, 基于 $\mathbf{T 1 0}$ 的 OLED 器件性能得 到大幅提升, $\mathrm{EQE}_{\text {max }}$ 高达 $15.5 \% 、 \mathrm{CE}_{\text {max }}$ 为 $15.4 \mathrm{~cd} \bullet \mathrm{A}^{-1}$ 、 $\mathrm{PE}_{\max }$ 为 $14.5 \mathrm{~lm} \cdot \mathrm{W}^{-1}, L_{\max }$ 超过 $16000 \mathrm{~cd} \cdot \mathrm{m}^{-2}$ 且器件寿命 延长了将近一倍, LT50 达 $78 \mathrm{~h}\left(L_{0}=500 \mathrm{~cd} \cdot \mathrm{m}^{-2}\right)$. 研究
结果表明引入 9-苯基芴基的化学方法简单高效，对应深 蓝光器件的综合性能优于化合物 $\mathbf{T} \mathbf{9}$, 处于最高水平行 列.

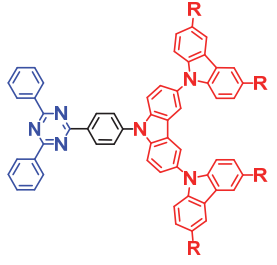

T1: $R=H$ $\mathrm{T} 2: \mathrm{R}=\mathrm{Ph}$

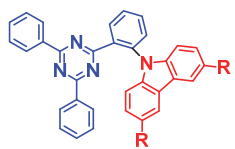

T6: $R=H$ T7: $R=M e$ T8: $\mathbf{R}=\mathrm{Bu}$

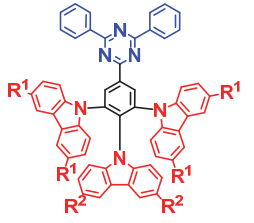

T3: $\mathbf{R}^{1}=\mathrm{R}^{2}=\mathrm{H}$ T5: $R^{1}=H, R^{2}=M e$

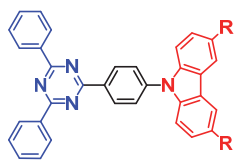

T9: $R=H$ T10: $\mathbf{R}=$

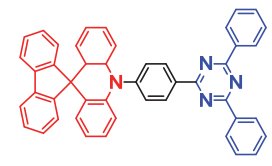

T13 T4: $R^{1}=R^{2}=M e$

图 5 含三嗪受体的给体单元取代基功能化 TADF 分子

Figure 5 Donor unit substitution functional TADF molecules with triazine-containing acceptor

鲐啶单元具有平面刚性和强大的供电子能力等特 点, 并且基于浐啶的 TADF 分子常表现出聚集诱导发光 增强(AIE $)^{[61]}$ 效应，可进一步提高材料的稳定性和发光 效率，因而被广泛应用于高效蓝光 TADF 分子的构建. 2016 年, $\mathrm{Wu}$ 和 Wong 团队 ${ }^{[62]}$ 在鲐啶单元上引入苯基和 螺二苯基团合成了三种三嗪类 TADF 分子 $\mathbf{T 1 1} \sim \mathbf{T 1 3}$ (图 5). 通过理论计算发现螺二茶会使得吅啶环更加平面 化, 而苯基会加大非平面化程度. 光谱数据显示苯基和 螺二苯都会导致吟啶供电子能力减弱, 发生蓝移. 电化 学测试也证明了取代基会提高 HOMO 能力、扩大能隙、 降低浐啶强度. 同时苯基和螺二苯都会增大 $\Delta E_{\mathrm{ST}}$, 两者 分别为 $0.072 \mathrm{eV}$ 和 $0.133 \mathrm{eV}$ (T11 为 $0.062 \mathrm{eV})$. 因螺二 苯的大体积、刚性、空间位阻的特点，使得 T13 在薄膜 中表现出 $100 \%$ 的 PLQY 和 $83 \%$ 的水平偶极子比 $(\Theta / /$, 所 有发射偶极子中水平偶极子的百分比), 相反 T12 的 PLQY 有所降低, $\Theta / /$ 为 78\%. 将化合物 $\mathbf{T 1 1} \sim \mathbf{T 1 3}$ 以质量 分数 12\%浓度掺杂到 9-(3-(9 氢-咔唑基-9-基)苯基)-9 氢咔唑-3-甲腈 $(\mathrm{mCPCN})$ 作为发光层制备了 OLED 器件, 发现螺二苯取代的 T13 器件性能最优, $\mathrm{EQE}_{\max }$ 为 $36.7 \%$, $\mathrm{CE}_{\max }$ 为 $94 \mathrm{~cd} \bullet \mathrm{A}^{-1}, \mathrm{PE}_{\max }$ 为 $98.4 \mathrm{~lm} \bullet \mathrm{W}^{-1}, \mathrm{CIE}$ 为 $(0.18$, 0.43), 而苯基取代的 T12 器件性能呈下降趋势. 
与引入取代基团类似, 将其他芳香环稠并到给体单 元上同样能对分子的构型、前线轨道能级和激发态能级 等物化特性产生影响, 从而对其电致发光性能起到调节 作用. 2016 年, Lee 等 ${ }^{[63]}$ 将苯并呋喃与咔唑单元进行稠 合后作为电子给体, 通过改变其与桥连亚苯基的连接位 点合成了三种三嗪类蓝光 TADF 分子 $T 14 \sim T 16$ (图 6). 二苯基三嗪和苯并呋喃咔唑基团具有良好的化学稳定 性, 确保了分子的 TADF 特性和优异稳定性, 且两个基 团的邻位相连可能会增强分子的 $\mathrm{CT}$ 特性降低 $\Delta E_{\mathrm{ST}}$, 且 给受体基团的扭曲会缩短分子的激发态寿命进而改善 器件的效率滚降问题. 理论计算结果表明邻位连接会造 成大的二面角和扭曲的 D-A 结构, 增强分子的 CT 特性, 从而降低单重态能量, 并且大的扭曲会导致共轭长度变 短, 提高三重态能量, 因此会导致分子的 $\Delta E_{\mathrm{ST}}$ 明显降 低. 通过光谱测试得到的实验值与理论值相近，T14、

$\mathrm{T} 15$ 和 $\mathrm{T} 16$ 的 $\Delta E_{\mathrm{ST}}$ 分别为 $0.002 \mathrm{eV} 、 0.191 \mathrm{eV}$ 和 0.302 $\mathrm{eV}$. 三者的延迟寿命和 PLQY 同样有所差异, $\tau_{\mathrm{d}}$ 分别为 $5.4 \mu \mathrm{s} 、 29.6 \mu \mathrm{s}$ 和 $31.2 \mu \mathrm{s}$; PLQY 为 $97.9 \%$ 、31.1\%和 $85.3 \%$. 将三种分子掺杂到 DPEPO 中作为发光层, TADF 器件结构为 ITO/PEDOT:PSS(60.0 nm)/TAPC(20.0 nm)/ $\mathrm{mCP}(10.0 \mathrm{~nm}) / \mathrm{DPEPO}: \mathrm{TADF}$ emitter(25.0 nm)/TSPO1 $(5.0 \mathrm{~nm}) / \mathrm{TPBi}(30.0 \mathrm{~nm}) / \mathrm{LiF}(1.5 \mathrm{~nm}) / \operatorname{Al}(200.0 \mathrm{~nm})$. 器件 性能结果表明具有高 PLQY 和短激发态寿命的 T14 表现 出最高的 $\mathrm{EQE}$ 和较小的效率滚降, 器件的 $\lambda_{\mathrm{EL}}$ 为 $477 \mathrm{~nm}$, $\mathrm{CIE}$ 坐标为 $(0.18,0.31), \mathrm{EQE}_{\max }$ 为 $20.4 \%$, 且 $\mathrm{EQE}_{100}(100$ $\mathrm{cd} \cdot \mathrm{m}^{-2}$ 亮度下的 $\left.\mathrm{EQE}\right)$ 和 $\mathrm{EQE}_{1000}\left(1000 \mathrm{~cd} \cdot \mathrm{m}^{-2}\right.$ 亮度下的 $\mathrm{EQE}$ )分别为 $20.0 \%$ 和 $17.7 \%$.

咔唑与三嗪基团简单结合形成的蓝光 TADF 分子 $\mathrm{T} 17$ 只有 $4.5 \%$ 的 $\mathrm{EQE}$ 和 $0.43 \mathrm{eV}$ 的 $\Delta E_{\mathrm{ST}}$. 为了提高材 料性能, Liao 等 ${ }^{[64]}$ 将 9,9'-螺二芴与咔唑相结合形成了一 种新的电子给体, 进而合成了两个新型蓝光 TADF 分子 T18 和 T19 (图 6). 9,9'-螺二芴的并入使得分子具有高的 热稳定性、理想的结构刚性和良好的成膜能力, 而桥连 苯基上的氟原子又可以调节分子的扭转角和 $\Delta E_{\mathrm{ST}}$, 其中 化合物 $\mathrm{T} 19$ 的 $\Delta E_{\mathrm{ST}}$ 为 $0.24 \mathrm{eV}$, 且具有 $1.0 \mu \mathrm{s}$ 的较短延 迟寿命, $2.9 \times 10^{5} \mathrm{~s}^{-1}$ 的 RISC 速率和 $51 \%$ 的 PLQY 值. 在 结构为 ITO/HAT-CN $(10 \mathrm{~nm}) / \mathrm{TAPC}(30 \mathrm{~nm}) / \mathrm{mCP}(10 \mathrm{~nm}) /$ DPEPO:TADF emitters(20 nm)/DPEPO(10 nm)/TmPyPB $(40 \mathrm{~nm}) / \operatorname{Liq}(2 \mathrm{~nm}) / \operatorname{Al}(120 \mathrm{~nm})$ 的 TADF-OLED 器件中, 两者都表现出蓝光发射. 使用 $\mathrm{T} 19$ 作为发射体的深蓝色 TADF-OLED 显示出良好的 CIE 坐标 $(0.16,0.17)$, 并展 示出更好的 $\mathrm{EL}$ 性能(7.21\%, $\left.11.16 \mathrm{~cd} \cdot \mathrm{A}^{-1}, 9.74 \mathrm{~lm} \bullet \mathrm{W}^{-1}\right)$. 同年，该课题组 ${ }^{[65]}$ 又将芴基和咔唑融合到咔唑供体上， 甲基引入到桥连单元上面, 设计合成了蓝光分子 $\mathbf{T 2 0}$. 实验表明弱给电子能力的咔唑给体的多重修饰对于构 建具有低滚降的高效蓝光 TADF 发射体效果显著. 芴基 与咔唑单元稠合形成咔唑基稠环给体, 大大提高了分子 的刚性, 从而提高分子的 PLQY. 而加入另外一个咔唑 基团可以分散 HOMO 能级的分布来减小 $\mathrm{HOMO}$ 与
LUMO 的重叠. 最后在亚苯基上接入甲基, 既调节了分 子的扭转角, 又减小分子的 $\Delta E_{\mathrm{ST}}$. 与原始的 $\mathrm{TADF}$ 分子 $\mathbf{T 1 7}$ 相比, 经过多重修饰的 T20 具有更显著的 TADF 特 性、更优异的热稳定性、更小的 $\Delta E_{\mathrm{ST}}$ 值 $(0.22 \mathrm{eV})$ 和更高 PLQY 值(84\%). 最终, 在天蓝色 OLED 中获得了 $18.7 \%$ 的高 $\mathrm{EQE}, 39.0 \mathrm{~cd} \cdot \mathrm{A}^{-1}$ 的 $\mathrm{CE}, 30.5 \mathrm{~lm} \cdot \mathrm{W}^{-1}$ 的 $\mathrm{PE}$, 而且随 着亮度增加到 $1000 \mathrm{~cd} \cdot \mathrm{m}^{-2}, \mathrm{EQE}$ 仍保持为 $14.8 \%$, 表明 器件具有较小的效率滚降.

Chi 等 ${ }^{[66]}$ 的研究结果表明狮并咔唑具有较高的空穴 迁移率和低的 ${ }^{3} \mathrm{LE}$, 可作为电子给体构筑蓝光 TADF 分 子. 2018 年, Wang 和 Dias 团队 [67]合作报道了四种含有不 同取代基和取代位置的狮并咔唑单元的蓝光 TADF 分子 $\mathbf{T 2 1} \sim \mathbf{T 2 4}$ (图 6). T21 T23 可分别通过在咔坐的 2,3 位 修饰芴基、二苯基和二甲基得到, T24 则是在咔唑 3,4 位 上修饰二苯基. 结果发现二苯基比芴基和二甲基修饰的 具有更高的热稳定性，但是 3,4 位修饰的比 2,3 位修饰的 热稳定性有所下降，但仍高于其他取代基修饰的化合 物. 理论计算得出 HOMO 能级会随着供电子能力增强 而提高, 而电子供体能力的顺序为芴基 $<$ 二苯基 $<$ 二甲 基. 对于相同的取代基，在咔唑上取代的 3,4 位比 2,3 位 表现出更强的供电子能力, 因此 T24 具有最高的 HOMO 能级. 理论计算与光谱数据都表明前三种分子 具有相似的共轭程度，但二甲基修饰的分子拥有最强的 $\mathrm{ICT}$ 特性和最低的三重态能量, 因此三者的 $\Delta E_{\mathrm{ST}}$ 分别为 $0.19 \mathrm{eV} 、 0.17 \mathrm{eV}$ 和 $0.15 \mathrm{eV}$; 但 $\mathbf{T} 24$ 具有不同的空间效 应和给电子能力, 使其具有较高的三线态能级, 故 $\Delta E_{\mathrm{ST}}$ 最小, 为 $0.11 \mathrm{eV}$. 四种分子的延迟组分随着 $\Delta E_{\mathrm{ST}}$ 减小 而增大, 延迟寿命逐渐缩短, PLQY 逐渐增加. 其中
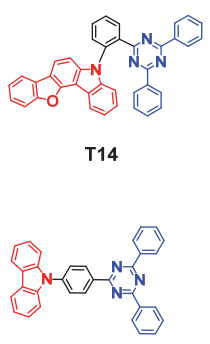

T17

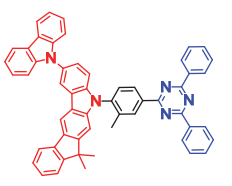

T20
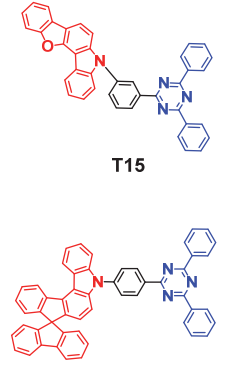

T18

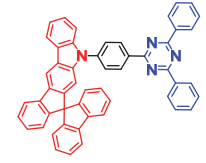

T21

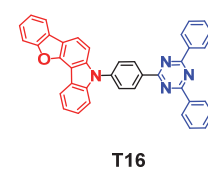

T16

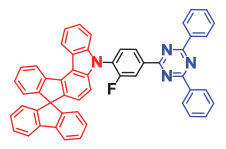

T19

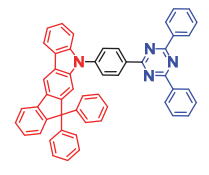

T22
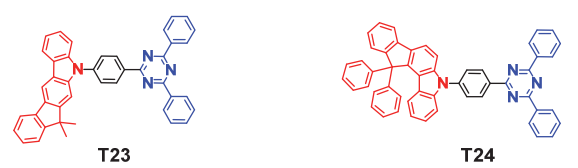

图 6 含稠环咔唑给体和三嗪受体的 TADF 分子

Figure 6 TADF molecules with ring-fused carbazole-based donor and triazine-containing acceptor 
PLQY 的增加主要归因于快速的辐射衰变过程. 以 $\mathrm{DPEPO}$ 为主体材料, TADF 分子掺杂浓度为质量分数 $10 \%$, 制备了结构为 $\mathrm{ITO} / \mathrm{MoO}_{3}(10 \mathrm{~nm}) / \mathrm{sNPB}(70 \sim 80$ $\mathrm{nm}) / \mathrm{mCP}(15 \sim 20 \mathrm{~nm}) / \operatorname{EML}(25 \mathrm{~nm}) / \operatorname{DPEPO}(10 \sim 15$ $\mathrm{nm}) / \mathrm{BPhen}(30 \sim 40 \mathrm{~nm}) / \mathrm{LiF}(1 \mathrm{~nm}) / \mathrm{Al}$ 的蓝光 OLED 器件. 其中基于 $\mathbf{T 2 4}$ 的器件表现出最优的器件性能, 最大 $\mathrm{EQE}$ 约为 $25.9 \%, \mathrm{CE}_{\max }$ 为 $44.6 \mathrm{~cd} \bullet \mathrm{A}^{-1}, \mathrm{PE}_{\max }$ 为 $34.3 \mathrm{~lm} \cdot \mathrm{W}^{-1}$, $\mathrm{CIE}$ 坐标为 $(0.15,0.24)$. 但四者的器件的效率滚降均较 大, 这可能是由较慢的 RISC 导致的 TTA 引起的.

在众多发表的三嗪类蓝光 TADF 分子中发现, 研究 者们常采用苯环作为桥连单元来连接给体与三嗪单元, 使得发光分子 HOMO 和 LUMO 在一定程度上的重叠, 进而保证化合物具有理想的 PLQY 值. 在桥连单元上, 甲基、甲氧基和苯基等取代基常被引入以调控发光分子 的物化特性和聚集态结构. 而叔丁基较少使用, 可能的 原因是其较大的空间位阻影响取代基的接入和分子的 有效共轭.

2016 年, Adachi 等 ${ }^{[53]}$ 在桥连单元上引入甲基以平衡 $\Delta E_{\mathrm{ST}}$ 与 PLQY 之间的矛盾关系, 设计合成了四种甲基修 饰的咔唑-三嗪类深蓝光 TADF 分子 T25 T T28(图 7), 考 察研究了甲基取代基个数和位置对蓝光分子物化性质 和器件性能的影响. T25 含有两个甲基, 分别在咔唑的 3 和 6 号位. 不论在亚苯基的 2 号位(T27), 还是同时在亚 苯基的 2 和 6 号位(T28)或者咔唑基团的 1 和 8 号位(T2) 引入甲基均会造成咔唑类给体与亚苯基之间的二面角 增加, 提高分子的 $\mathrm{T}_{1}$ 能级, 降低 $\Delta E_{\mathrm{ST}}$. 不同的是, 在 3,6-二甲基咔唑的 1 和 8 号位引入的两个甲基有效地降 低了分子的电离势, 导致其 ${ }^{3} \mathrm{CT}$ 能级比 ${ }^{3} \mathrm{LE}$ 低, 因而化 合物 $\mathbf{T} 2$ 的 $\mathrm{T}_{1}$ 主要由 ${ }^{3} \mathrm{CT}$ 控制. 而其他三者的 $\mathrm{T}_{1}$ 则主要 由 ${ }^{3} \mathrm{LE}$ 控制. 以 DPEPO:TADF 材料 $(w=6 \%)$ 为发光层制 备的 OLED 器件均表现出蓝光发射和较高的 EQE. 化合 物 T25、T27、T28 的器件呈现深蓝光发射, 而 T26 表 现为天蓝光. 基于一个甲基修饰的亚苯基的 $\mathbf{T} 27$ 器件表 现出最优的深蓝光发射, 其 $\mathrm{EQE}_{\text {max }}$ 为 $19.2 \%, \mathrm{CIE}$ 色坐 标为 $(0.148,0.098)$, 这在当时是最优秀的深蓝光性能之

接着 $\mathrm{Lee}^{[68]} 、 \mathrm{Kim}^{[69]} 、$ Buchwald ${ }^{[70]}$ 等对以三嗪为受 体, 亚苯基为桥连单元的蓝光 TADF 分子体系做了进一 步的修饰和改进. 2017 年, Lee 等[68]使用甲氧基单元来 修饰桥连基团, 开发了发射光谱蓝移的 TADF 分子 T29 T31 (图 7), 并系统研究了甲氧基单元数量对材料 和 TADF-OLED 的器件性能的影响. T29 和 T30 中存在 的氢键作用使其保持平面结构, 两者的二面角保持在 $3.30^{\circ}$ 左右, 而 $\mathrm{T} 31$ 因两个甲氧基取代, 导致氢键断裂, 二面角突增至 $72.11^{\circ}$. 甲氧基减少了供体和受体之间的 分子间电子相互作用，使发射波长逐渐从 T29 (473 nm) 和 T30 (457 nm)蓝移到 T31 (424 nm), 并且会降低分子 的 CT 特性. 同时发现甲氧基的数量对 PLQY 影响显著,
T30 的 PLQY 接近 100\%, 而含有两个甲氧基的 T31 只 有 $19 \%$. 以上述分子为发光客体, DPEPO 为主体，掺杂 浓度为质量分数 $30 \%$ 制备得到了蓝光 OLED 器件. T29 和 $\mathbf{T} 30$ 的器件都表现出 $21.2 \%$ 的 $\mathrm{EQE}_{\max }$, 而 $\mathrm{T} 31$ 的 $\mathrm{EQE}_{\max }$ 却只有 $13 \%$, 这可能是由于它具有低的 PLQY 和 大的 $\Delta E_{\mathrm{ST}}$. 该结果表明, 桥连单元上连接适当数量的甲 氧基可以使发射光谱发生蓝移, 同时又不会损害发光器 件的 EQE.

Kim 团队 ${ }^{[69]}$ 改用螺环呋啶为给体, 在亚苯基桥联单 元引入甲基, 制备了 3 种 D-A 型分子 $\mathbf{T 3 2} \sim \mathbf{T 3 4}$ (图 7). 理论研究发现，引入甲基对分子的 $\Delta E_{\mathrm{ST}}$ 几乎没有影响; T32 呈平面构型, T33 构型与 T32 相差不大, 但 T34 的 给体与亚苯基之间的二面角为 $25.5^{\circ}$, 扭曲程度明显提 升. 随着甲基引入数量的增加, 共轭桥与三嗪基团间的 二面角逐渐增大, 扭曲程度加大，有效共轭长度减小使 得 TADF 分子发射蓝移. 与没有甲基修饰的分子相比, 含有甲基的 TADF 分子表现出更小的 PLQY 与更短的 $\tau_{\mathrm{d}}$, 其中 T34 分子纯膜的 PLQY 为 $43 \%, \tau_{\mathrm{d}}$ 为 $2.8 \mu \mathrm{s}$. 同时, 甲基的引入也使得分子的 $\Theta / /$ 降低，这将不利于 $E Q E$ 的 提升. 以 DPEPO 为主体材料, 掺杂浓度为质量分数 $12 \%$ 的 TADF 材料作为发光层制备的 OLED 器件, 基于 T33 和 T34 的器件电致发光蓝移, 其 CIE 分别为 $(0.148$, $0.158)$ 和( $0.148,0.131), \mathrm{EQE}_{\text {max }}$ 亦达到 $23.7 \%$ 和 $16 \%$.

而 Buchwald 等[70]则改用亚氨基二苠给体单元，设 计合成了四种蓝光 $\mathrm{TADF}$ 分子 $\mathbf{T 3 5} \sim \mathbf{T 3 8}$ (图 7). 考察了 桥连单元上接入甲基的数量对于器件性能的影响. 甲基 数量的增加会使二面角增大, 分子的结构刚度得到提 升, $\Delta E_{\mathrm{ST}}$ 和斯托克斯位移减小, 延迟苂光寿命缩短, RISC 速率得到提高. 其中化合物 $\mathbf{T 3 8}$ 有着 $78.0^{\circ}$ 的二面 角, 小到为 0 的 $\Delta E_{\mathrm{ST}}$ 和 $6 \mu \mathrm{s}$ 的延迟寿命. 化合物 T35 T37 的 PLQY 因结构刚度增加而提高, 化合物 T37 达到 了 $98 \%$ 的高 PLQY, 而化合物 T38 因荧光辐射过程较慢, PLQY 大大降低，仅有 $37 \%$. 掺杂浓度为质量分数 $20 \%$ TADF 材料作为发光层用来制备的 OLED 器件均表现出 蓝光发射. 引入的甲基增加了结构刚度，从而提高了 $\mathrm{EQE}$, 最高提升了四倍. 化合物 $\mathbf{T 3 5} \sim \mathbf{T 3 8}$ 的器件 $\mathrm{EQE}_{\text {max }}$ 分别为 $6.8 \% 、 12.3 \% 、 28.3 \%$ 和 $16.4 \%, \mathrm{CIE}$ 坐标 分别为 $(0.18,0.25) 、(0.22,0.39) 、(0.21,0.44)$ 和 $(0.20$, $0.30)$.

最近, Lee 等 ${ }^{[71]}$ 在 Adachi 课题组 ${ }^{[57]}$ T39 的基础上, 合成了蓝光 TADF 分子 $\mathbf{T 4 0}$ 和 $\mathbf{T 4 1}$ (图 7), 考察了共轭苯 基接入桥连单元对分子性质和器件性能产生的影响. 结 果发现随着引入苯基数量增加, $\mathrm{CT}$ 特性明显增强, 降低 了 $\Delta E_{\mathrm{ST}}$ 和 $\tau_{\mathrm{d}}$, 实现了高效的 RISC 过程. 空间位阻增大 从而增加骨架的刚性，抑制了非辐射过程，进而提高了 PLQY. 其中 T41 表现出 $0.11 \mathrm{eV}$ 的 $\Delta E_{\mathrm{ST}}$ 和 $90 \%$ 的 PLQY. 以 $\operatorname{ITO}(50 \mathrm{~nm}) / \operatorname{PEDOT}: \operatorname{PSS}(60 \mathrm{~nm}) / \mathrm{TAPC}(20 \mathrm{~nm}) / \mathrm{mCP}$ $(10 \mathrm{~nm}) / \mathrm{DPEPO}: \operatorname{dopant}(w=20 \%, 25 \mathrm{~nm}) / \mathrm{TSPO} 1(5 \mathrm{~nm}) /$ 
$\operatorname{TPBi}(40 \mathrm{~nm}) / \operatorname{LiF}(1.5 \mathrm{~nm}) / \mathrm{Al}(200 \mathrm{~nm})$ 为结构制备蓝光发 射的 OLED 器件. 尽管苯基的引入会阻碍载流子的迁移 导致电流密度下降, 但能有效提升器件的 $\mathrm{EQE}$ 并改善 效率滚降问题. 基于 $\mathbf{T 4 1}$ 的 OLED 器件的 $\mathrm{EQE}_{\max }$ 为 $28.5 \%, \mathrm{EQE}_{1000}$ 为 $19.4 \%, \mathrm{PE}_{\max }$ 为 $57.1 \mathrm{~lm} \bullet \mathrm{W}^{-1}, \mathrm{CE}_{\max }$ 为 $64.4 \mathrm{~cd} \cdot \mathrm{A}^{-1}$.

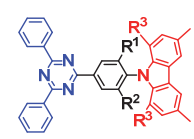

T25: $R^{1}=R^{2}=H$ T26: $R^{1}=R^{2}=H, R^{3}=M e$ T27: $R^{1}=M e, R^{2}=R^{3}=H$ T28 $R^{1}=R^{2}=M e, R^{3}=H$

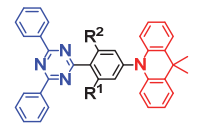

T29: $R^{1}=R^{2}=H$ T30: $R^{1}=O M e, R^{2}=H$ T31: $R^{1}=R^{2}=$ OMe

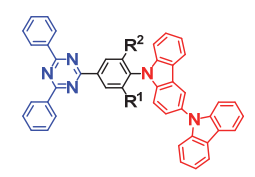

T39: $\mathbf{R}^{1}=\mathbf{R}^{2}=\mathrm{H}$ T41: $R^{1}=R^{2}=P h$ T40: $R^{1}=P h, R^{2}=H$
T32: $R^{1}=R^{2}=H$ T33: $R^{1}=M e, R^{2}=H$ T34: $R^{1}=R^{2}=M e$

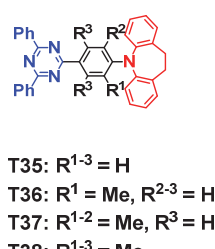

T37: $R^{1-2}=M e, R^{1-3}=M e$

图 7 含三嗪受体的桥连单元取代基功能化的 TADF 分子

Figure 7 Bridge unit substitution functional TADF molecules with triazine-containing acceptor

\section{4 砜类}

二苯砜具有良好的吸电子能力, 在分子中心时呈现 出一定的扭转角, 常作为电子受体用以构建 D-A 型 $\mathrm{TADF}$ 分子, 尤其是蓝光 TADF 分子. 同时与咔唑单元 相比, 二苯胺单元具有更深的 HOMO 能级 ${ }^{[72]}$, 更强的 供电子能力和 ICT 特性以及更低的单线态能量, 也是构 筑 TADF 分子的常见电子给体. Adachi 课题组 ${ }^{[42]}$ 首次以 二苯砜为电子受体, 分别以二苯胺、叔丁基二苯胺合成 了 2 种蓝光 $\mathrm{TADF}$ 分子 $\mathbf{S 1} \sim \mathbf{S 2}$ (图 8). 研究发现通过引 入叔丁基能够增强二苯胺单元的给电子能力, 从而降低 了 ICT 能量, 进而获得了比化合物 $\mathrm{S} 1$ 更低的 $\Delta E_{\mathrm{ST}}$ 值 $(0.45 \mathrm{eV})$. 两种分子以 DPEPO 为主体材料掺杂的薄膜 均显示较纯的蓝光, PLQY 分别为 $60 \%$ 和 $66 \%$. 器件结 构采用 ITO $/ \alpha-\mathrm{NPD}(30 \mathrm{~nm}) / \mathrm{TCTA}(20 \mathrm{~nm}) / \mathrm{CzSi}(10 \mathrm{~nm}) /$ DPEPO:S1 $\sim \mathbf{S 2}(w=10 \%, 20 \mathrm{~nm}) / \operatorname{DPEPO}(10 \mathrm{~nm}) /$ $\mathrm{TPBi}(30 \mathrm{~nm}) / \mathrm{LiF}(1 \mathrm{~nm}) / \mathrm{Al}$, 两者对应的 $\mathrm{EQE}_{\max }$ 分别为 $2.9 \%$ 和 $5.6 \%$. 叔丁基的引入能够有效提高器件 $\mathrm{EQE}$, 然而不足之处在于器件表现出较大的效率滚降和较小 的发光亮度.

2016 年, Lee 等[73]将联苯砜强受体与咔唑弱给体结 合开发出天蓝光和绿光 TADF 分子 $\mathbf{S 3}$ 和 $\mathbf{S 4}$ (图 8). 与 S3 分子相比, 叔丁基修饰的化合物 S4 其 HOMO 和 LUMO 能级更高, $\mathrm{S}_{1}$ 与 $\mathrm{T}_{1}$ 态能量更低, CT 特性更强, 这 是因为叔丁基的引入增强了咔唑的给电子能力. 化合物 $\mathbf{S 4}$ 呈现出更小的 $\Delta E_{\mathrm{ST}}(0.05 \mathrm{eV})$ 、更高的 PLQY $(92 \%)$ 和较短的延迟苂光寿命 $(1.13 \mu \mathrm{s})$. 两种分子以 $\mathrm{ITO}(120$ $\mathrm{nm}) / \operatorname{PEDOT}: \operatorname{PSS}(60 \mathrm{~nm}) / \operatorname{TAPC}(20 \mathrm{~nm}) / \mathrm{mCP}(10 \mathrm{~nm}) /$

$\operatorname{EML}(25 \mathrm{~nm}) / \mathrm{TSPO} 1(5 \mathrm{~nm}) / \mathrm{TPBI}(30 \mathrm{~nm}) / \mathrm{LiF}(1 \mathrm{~nm}) / \mathrm{Al}$ (200 nm) 器件结构制备 OLED 器件并测试其性能, 两种 器件分别呈现天蓝光和绿光发射, CIE 坐标分别为 $(0.213,0.393)$ 和 $(0.289,0.522)$. 对比发现叔丁基单元会 阻碍空穴传输, 导致电流密度 $J$ 降低, 进而导致 EQE 下 降, 同时色坐标偏移较大, 使得 EL 发射由天蓝光红移 为绿光.

在构建蓝光 TADF 分子上, 双(苯磺酰基)苯(BPSB) 比二苯砜具有更小的 $\Delta E_{\mathrm{ST}}{ }^{[74]}$, 但溶解性相对较差. 为改 善此问题, Bunz 和 Hernandez-Sosa 团队 [74]将 BPSB 受 体、甲基和叔丁基功能化的二芳基胺给体进行结合，制 备得到一系列可溶液加工的蓝光 TADF 化合物 $\mathbf{S 5} \sim \mathbf{S 8}$ (图 8). 在 $\mathbf{S 5} \sim \mathbf{S 8}$ 中，二苯胺单元中氮的对位没有甲基 或叔丁基时即为分子 $\mathbf{S 6}$, 在溶液状态下具有最为蓝移 的最大吸收波长和最大发射波长. 研究发现无烷基修饰 的 S6 溶液具有 TADF 特性但其聚甲基丙烯酸甲酯 (PMMA)掺杂薄膜无明显 TADF 特性，而烷基取代基的 引入可以保证蓝光 TADF 特性并增强化合物的溶解性. S8 含有两个较大空间位阻的叔丁基，亚苯基和二苯胺 之间的二面角在四者中最大，因而其溶液状态下延迟组 分也最大. 将化合物 $\mathbf{S 6} \sim \mathbf{S 8}$ 掺杂到 2,6-双( $N$-咔唑基)吡 啶(PYD2)作为发光层制备了 OLED 器件, 发现基于 S6 的器件在 $\mathrm{EQE}_{\max } 、 L_{\max }$ 和色纯度方面都具有较好的表现, 分别为 $8.5 \% 、 9751 \mathrm{~cd} \bullet \mathrm{m}^{-2}$ 和 CIE 色坐标为 $(0.16,0.08)$. 相反, 基于 $\mathbf{S 7}$ 和 $\mathbf{S 8}$ 的器件在 $\mathrm{CE}_{\max }$ 和 $\mathrm{PE}_{\max }$ 性能方面 较优, 其中基于 $\mathbf{S} 7$ 器件的 $\mathrm{CE}_{\max }$ 为 $7.5 \mathrm{~cd} \cdot \mathrm{A}^{-1}, \mathrm{PE}_{\max }$ 为 $4.5 \mathrm{~lm} \bullet \mathrm{W}^{-1}$. 该工作进一步表明 TADF 分子中烷基取代 基的个数和取代位置与最终器件性能有着密切关联.

2019 年, Dias 和 Bryce 团队 [46]报道了基于鲐啶与二 苯并噻吩的蓝光 $\mathrm{TADF}$ 分子 $\mathbf{S 9} \sim \mathbf{S 1 1}$ (图 8). 通过在呋啶 给体上引入叔丁基与甲氧基来微调 $\mathrm{D}-\mathrm{A}$ 单元之间的电 子相互作用，达到控制 TADF 机制实现深蓝光的目标. 研究发现无取代的 S9 分子具有 RTP 效应, 引入两个取 代基之后, 发光机制从 RTP 转换为 TADF 机制. 理论计 算发现，两个取代基都会增强吅啶单元的给电子能力, 叔丁基会降低 $\mathrm{S}_{1}$ 态能量, 从而降低 $\Delta E_{\mathrm{ST}}$; 而甲氧基会增 大电子云密度, 同时降低 $\mathrm{S}_{1}$ 与 $\mathrm{T}_{1}$ 能量, $\Delta E_{\mathrm{ST}}$ 却有所升高. 因反应活性位点被封堵, 电化学稳定性得以提高. PL 光 谱显示，甲氧基比叔丁基红移更明显, HOMO 能级更高. 叔丁基使得三线态由 ${ }^{3} \mathrm{LE}$ 控制，而甲氧基控制三线态主 要为 ${ }^{3} \mathrm{CT}$, 叔丁基对 PLQY 提升效果比甲氧基更明显. 其掺杂型蓝光 OLED 器件最大 EQE 为 $10.5 \%$, CIE 坐标 达 $(0.13,0.129)$.

近期, $\mathrm{Li}$ 和 $\mathrm{Ma}$ 团队 ${ }^{[75]}$ 利用不同长度烷基修饰的浐 啶基团与二苯砜受体合成了 5 种蓝光 TADF 分子 $\mathbf{S 1 2}$ S16 (图 8). 在浐定的 9 号位引入甲基至戊基的烷基链来 调控分子的电致发光性能. 5 个分子的紫外-可见吸收与 PL 发射光谱基本相似, 且均具有 AIE 特性, 拥有相同的 $\mathrm{HOMO}$ 能级与能隙 $E_{\mathrm{g}}$. 同时对应的 $\Delta E_{\mathrm{ST}}$ 数值均满足 
TADF 要求, 其中 $\mathbf{S 1 5}$ 和 $\mathbf{S 1 6}$ 较大, 分别为 $0.11 \mathrm{eV}$ 和 $0.07 \mathrm{eV}$. 除 D73 分子, 薄膜的 PLQY 随着链长增加而增 加, 最大为 $84.7 \%$. 理论计算研究证实烷基链不会影响 分子的前沿轨道能级, 但会明显影响其晶体的排列方 式. 晶体数据表明, S12 很难发生分子间电荷转移; S13 和 S14 均存在氢键作用, S13 有强烈的分子间作用力; S14 S16 分子堆积松散密度低, 其中 S16 的分子间作用 力最弱. 烷基链阻碍分子的紧密堆积并削弱分子间作用 力, 从而抑制了浓度淬灭. 作者采用了双主客体发射层 策略来提高 EL 效率, 所有器件的 EL 光谱基本相似, 且 均呈蓝光发射. S13 和 S14 器件因较强的分子间相互作 用而性能提升, S15 和 S16 因长烷基链干扰主客体之间 的作用导致性能下降. 其中含有乙基的 S13 器件性能最 优, $\mathrm{CE}_{\max }, \mathrm{PE}_{\max }$ 和 $\mathrm{EQE}_{\max }$ 增加到 $36.9 \mathrm{~cd} \cdot \mathrm{A}^{-1} 、 32.6$ $\mathrm{lm} \cdot \mathrm{W}^{-1}$ 和 $24.1 \%$.

2019 年, Monkman 团队 [76]发现在受体噻吨衍生物 引入甲基能够实现更高效电致蓝光发射. 他们以 $9,10-$ 二氢-9,9-二甲基呋啶为供体, 9,9-二甲基- $9 H$-噻吨-10,10二氧化物为受体, 构建了 D-A-D 型蓝光 TADF 分子 S17 和 S18(图 8). 在化合物 S18 中, 电子受体 2,6 位的甲基 取代基可以有效调节其强度, 进而在几乎不影响分子带 隙的同时调节 $S_{1}$ 和 $T_{1}$ 能级, 并且增加的 D-A 扭转角使 得光致发光光谱蓝移. 此外, 更加扭曲的结构导致了分 子具有更小的 $\Delta E_{\mathrm{ST}}(0.05 \mathrm{eV})$ 、更短的延迟寿命 $(3 \mu \mathrm{s})$ 和 更快的 $K_{\text {RISC }}\left(2.8 \times 10^{6} \mathrm{~s}^{-1}\right)$. 以 DPEPO 为主体材料, TADF 材料掺杂浓度为质量分数 $30 \%$ 作为发光层, 结构采用 ITO/NPB(40 nm)/TSBPA(10 nm)/EML(30 nm)/DPEPO

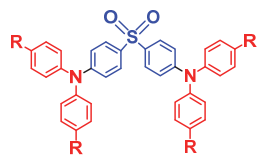

S1: $R=H$
S2: $R=B U$
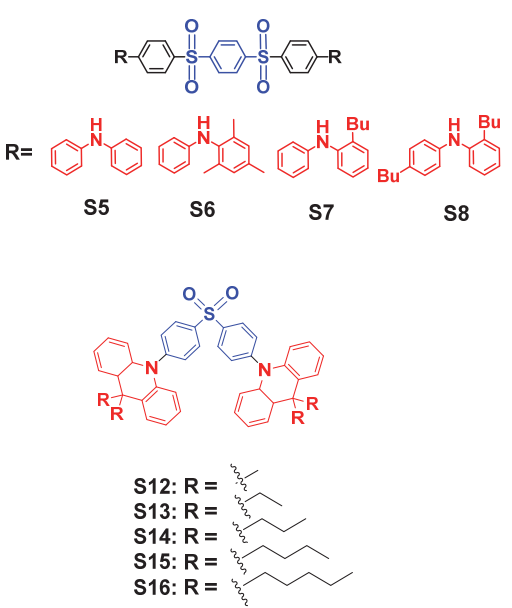

图 8 含砜类受体的 TADF 分子

Figure 8 TADF molecules with sulfone-containing acceptor
$(10 \mathrm{~nm}) / \mathrm{TPBi}(40 \mathrm{~nm}) / \mathrm{LiF} / \mathrm{Al}$ 制备得到 OLED 器件, 两种 器件均呈蓝光发射. 但含有取代基的 TADF 分子对应的 器件 $\mathrm{EL}$ 光谱更为蓝移, $\mathrm{EQE}_{\max }$ 更大为 $22.6 \%$, 并且在亮 度为 $1000 \mathrm{~cd} \cdot \mathrm{m}^{-2}$ 时具有 $(0.15,0.18)$ 的 CIE 坐标, 然而器 件的最大发光亮度较低, 仅为 $2765 \mathrm{~cd} \cdot \mathrm{m}^{-2}$.

\section{5 嘧啶类与噁二唑类}

嘧啶环跟各类电子给体之间具有良好的电子转移 效应 ${ }^{[77]}$, 并且与咔唑、噁二唑以及咪唑等单元相比具有 更低的 LUMO 能级 ${ }^{[78]} .2016$ 年, Kido 等 ${ }^{[79]}$ 以嘧啶衍生物 为电子受体，9,9-二甲基听啶为电子给体，设计合成了 三种 D-A-D 型 TADF 分子 $\mathbf{N 1} \sim \mathbf{N} 3$ (图 9), 考察了电子 受体上甲基和苯基取代基对发光分子及 OLED 器件的 影响.甲基和苯基取代基相较于氢原子(无取代)具有更 强的供电子能力, 故 $\mathbf{N 2}$ 和 $\mathbf{N 3}$ 表现出更浅的 LUMO 能 级和更宽的带隙，因而发射波长发生蓝移. 三者荧光最 大发射波长分别为 489,484 和 $478 \mathrm{~nm}$. 此外, 含有苯基 和甲基取代基的 TADF 分子掺杂薄膜具有稍高的 PLQY 值, 其中 N3 化合物展示出较高的 PLQY, 为 $80 \%$. 以 DPEPO 为主体, 三种 TADF 分子为发光客体, 客体掺杂 浓度为质量分数 $10 \%$ 作为发光层, 器件结构采用 ITO/TAPC (30 nm)/DPEPO:N1 $\sim \mathbf{N 3}(w=10 \%, 20 \mathrm{~nm}) /$ $\mathrm{B} 3 \mathrm{PyPB}(50 \mathrm{~nm}) / \mathrm{LiF}(0.5 \mathrm{~nm}) / \mathrm{Al}(100 \mathrm{~nm})$ 制备得到了 OLED 器件. N1 和 $\mathbf{N} 2$ 制备的器件均呈现出绿光发射, 而 N3 对应的器件发射天蓝光, 三者 CIE 色坐标分别为 $(0.21,0.44),(0.21,0.44)$ 和 $(0.19,0.37) ; \mathrm{EQE}_{\text {max }}$ 分别为 $20.9 \% ， 19.0 \%$ 和 $24.5 \%$. 值得说明的是，基于 $\mathbf{N} 3$ 的 OLED 器件的启亮电压仅为 $2.80 \mathrm{~V}$. 两年后, Zhao 团 队 ${ }^{[80]}$ 用 $10 H$-螺[二氢呋啶-9,9'-荡](SPAc)替换了 9,9-二甲 基叫啶, 合成了三种新 TADF 分子 $\mathbf{N 4} \sim \mathbf{N} 6$ (图 9). 在该 体系中, 甲基取代的 TADF 分子带隙最宽, 荧光最大发 射波长也最为蓝移, 这与呋啶体系的略有不同. 同时, 取代基的引入对分子掺杂薄膜的 PLQY 没有明显影响, 其中甲基取代基的 TADF 分子 PLQY 最小. 理论计算发 现三个分子的二面角接近 $90^{\circ}, \Delta E_{\mathrm{ST}}$ 较小. $\mathrm{HOMO}$ 与 LUMO 在桥连单元有重叠, 可有效促进分子的辐射衰 减. 以 DPEPO 为主体材料, 分别掺杂三种 TADF 材料作 为发光层制备了 OLED, 器件结构为 $\mathrm{ITO} / \mathrm{HATCN}(5$ $\mathrm{nm}) / \mathrm{TAPC}(30 \mathrm{~nm}) / \mathrm{mCP}(10 \mathrm{~nm}) / \operatorname{EML}(20 \mathrm{~nm}) / \operatorname{DPEPO}(5$ $\mathrm{nm}) / \mathrm{TPBi}(40 \mathrm{~nm}) / \mathrm{LiF}(0.9 \mathrm{~nm}) / \mathrm{Al}(100 \mathrm{~nm})$, 器件均呈蓝 光发射, 其发射峰值分别为 $487 \mathrm{~nm}, 479 \mathrm{~nm}$ 和 $484 \mathrm{~nm}$, $\mathrm{EQE}_{\max }$ 为 $25.56 \%, 24.34 \%$ 和 $31.45 \%$. 值得注意的是，基 于 N6 的器件为当时少数 $\mathrm{EQE}$ 超过 $30 \%$ 的蓝色 TADF 器件.

在更为复杂的螺叫啶衍生物给体中, 使用苯基调控 可同时获得深蓝色 TADF 材料的优异 EL 效率和高色纯 度. 2017 年, Yasuda 等 ${ }^{[81]}$ 报道了一系列以嘧啶衍生物为 电子受体, 螺鲐啶衍生物为电子给体的蓝光 TADF 分子 N7 N10 (图 9)，研究比较了其 TADF 分子物化特性及 
OLED 器件性能. 螺听啶单元与苯基共轭桥呈近乎正交 的结构, 而由于苯基取代基位于嘧啶基团上, 这对二面 角无明显影响. 苯基的引入使得受体基团拉电子能力有 所减弱, ICT 减弱, 因而分子的苂光最大发射波长略微 蓝移; 同时分子 LUMO 能级轻微提高, $\Delta E_{\mathrm{ST}}$ 略有减小, 但 $\tau_{\mathrm{d}}$ 下降明显且 PLQY 更小. 将 TADF 分子分别掺杂到 PPF 主体材料中作为发光层制备的 OLED 器件均表现出 蓝光发射. 虽然器件色坐标几乎不变, 但苯基对于不同 给体体系的器件 EQE、CE、PE 等性能则表现出不同的 趋势, 化合物 N7 的器件性能略有提高, 而化合物 N9 的 器件则略有降低. 其中基于 N7 的 OLED 的性能最优, $\mathrm{EQE}_{\text {max }} 、 \mathrm{CE}_{\text {max }}$ 和 $P E_{\text {max }}$ 分别为 $20.4 \% 、 41.7 \mathrm{~cd} \cdot \mathrm{A}^{-1}$ 和 $37.2 \mathrm{~lm} \cdot \mathrm{W}^{-1}$.

2017 年, Kido 团队 ${ }^{[82]}$ 在鲐啶-嘧啶类蓝光分子体系 中考察了亚苯基和嘧啶基团上甲基的取代基效应，合成 了化合物 N11 N13 (图 9). 化合物 N11 在嘧啶上引入一 个甲基, N12 在亚苯基上引入两个甲基, N13 同时在亚苯 基和嘧啶基团上引入甲基. 受体与亚苯桥分别引入甲 基, 二面角变化不大, 但同时引入后二面角增大两倍, $\pi$ 共轭长度降低, 其中 N13 具有较弱的 ICT 特性和较大的 带隙 $\left(E_{\mathrm{g}}\right)$, 并且通过调节电子激发态能量的方式来降低 $\tau_{\mathrm{d}}$, 使得 $\mathrm{N13}$ 分子的延迟寿命缩短了 $5 \mu \mathrm{s}$. 制备 ITO/ PPBI(20 nm)/TAPC(20 nm)/mCP(10 nm)/DPEPO:N11 $\mathbf{N 1 3}(w=20 \%, 20 \mathrm{~nm}) / \operatorname{DPEPO}(10 \mathrm{~nm}) / \operatorname{B3PyPB}(30 \mathrm{~nm}) /$ $\operatorname{LiF}(0.5 \mathrm{~nm}) / \mathrm{Al}(100 \mathrm{~nm})$ 结构的 TADF-OLED 器件. 三者 都表现出蓝光发射, 其中 N13 的纯蓝色 OLED 的 $\mathrm{EQE}_{\max }$ 为 $18 \%$, 开启电压降至 $3.25 \mathrm{~V}, \mathrm{CIE}$ 坐标为 $(0.16$, 0.15)以及达到了 $20 \mathrm{~lm} \cdot \mathrm{W}^{-1}$ 的高 $\mathrm{PE}$.

噁二唑类受体三线态能级较高, 吸电子性良好, 电 子注入与传输能力优异, 被广泛用作构建 D-A 型蓝光 TADF-OLED ${ }^{[83-84]}$. Wong 课题组 ${ }^{[85]}$ 以含氰基化合物 N14 为起始反应物, 通过两步反应合成了四种噁二唑基团为 受体, 咔唑为给体的蓝光 TADF 分子 N15 N18 (图 9), 并考察受体单元上四种不同的取代基对发光分子物化 性质及器件性能的影响. 取代基的引入会对电子受体拉 电子能力起到有效的调节, 使得分子的 ICT 得以改变, 进而影响 TADF 分子的吸收和发光光谱. 在溶液状态下, 四种分子的最大发射波长呈现出的趋势是 $\mathrm{N15}<\mathrm{N} 18<$ $\mathbf{N 1 6}<\mathrm{N17}$, 这与电化学测试所得的分子带隙是一致的. 与 N14 中的氰基相比, 取代基修饰的噁二唑单元具有更 弱的拉电子能力. 因此这四种 TADF 分子表现出更为蓝 移的发光光谱且 LUMO 能级比 N14 $(-2.97 \mathrm{eV})$ 更高, 其中化合物 $\mathbf{N 1 5}$ 的最高, 为 $-2.70 \mathrm{eV}$. 根据这些分子的 LUMO 能级的高低, 将其掺杂在主体 PPT 或 mCP 中, 构 成结构为 $\operatorname{ITO}(90 \mathrm{~nm}) / \mathrm{NPB}(35 \mathrm{~nm}) / \mathrm{mCP}(10 \mathrm{~nm}) / \mathrm{EML}(15$ $\mathrm{nm}) / \mathrm{PPT}(10 \mathrm{~nm}) / \mathrm{TmPyPB}(30 \mathrm{~nm}) / \mathrm{LiF}(1 \mathrm{~nm}) / \operatorname{Al}(100 \mathrm{~nm})$ 的 OLED 器件. 基于 N14 和 N17 的器件呈天蓝光发射, 其他器件则发射深蓝光. 其中含有 N18 的器件 EL 光谱
最为蓝移，最大发射波长为 $446 \mathrm{~nm}, \mathrm{CIE}$ 色坐标为 $(0.15$, 0.11 ), 但 $\mathrm{EQE}_{\max }$ 相对较小为 $6.6 \%$. 当取代基为 $4-$ 三氟 甲基苯基时，其 $\mathrm{CIE}$ 色坐标为 $(0.16,0.25), \mathrm{EQE}_{\max }$ 提升 到 $11.2 \%$, 而基于 N14 的器件 EL 光谱红移更明显, CIE 色坐标为 $(0.16,0.30)$, 同时 $\mathrm{EQE}_{\text {max }}$ 增加到 $14.0 \%$. 由此 可见，不同电子受体或受体单元上的不同取代基会对发 光分子的 EL 特性产生重要影响.
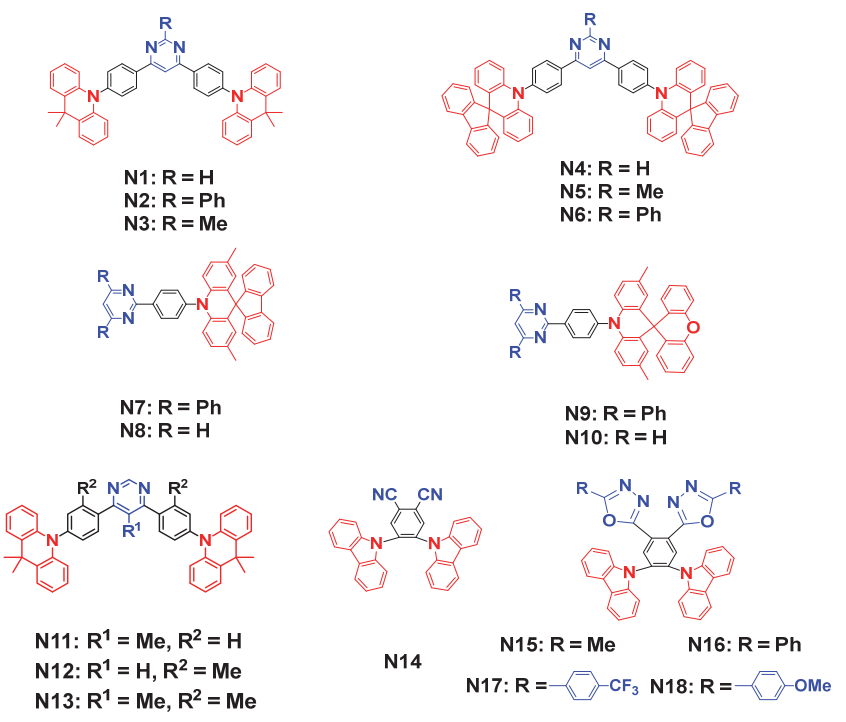

图 9 含嘧啶类与噁二唑类受体的 TADF 分子

Figure 9 TADF molecules with pyrimidine and oxadiazole-containing acceptor

\section{6 其他类}

与二苯砜类似, 含有缺电子羰基的二苯甲酮其羰基 与苯环存在较大的扭转角, 也是一种常见的构建 D-A 型 $\mathrm{TADF}$ 蓝光分子的电子受体. 2016 年, Cheng 等 ${ }^{\left[{ }^{[6]} \text { 以苯甲 }\right.}$ 酰基吡啶作为电子受体合成了四种咔唑基 $\mathrm{TADF}$ 蓝光分 子 O1 O4 (图 10), 考察了咔唑 3,6 位上的叔丁基和咔 唑取代基对分子物化性质和器件性能的影响. DFT 计算 结果显示 03 和 04 的 HOMO 和 LUMO 分离良好, 优于 01 和 02 . 实验研究结果表明具有给电子能力的叔丁基 和咔唑取代基导致分子最大发射波长明显红移，降低了 分子的带陌, 且咔唑取代基效果更加显著. 而在 3 号位 引入一个咔唑和 3,6 位同时被咔唑基团取代则红移程度 明显减弱. 同时上述取代基的引入大幅度改善了 $\Delta E_{\mathrm{ST}}$ 和 PLQY, $\Delta E_{\mathrm{ST}}$ 依次减小, 04 的 $\Delta E_{\mathrm{ST}}$ 最小, 为 $0.05 \mathrm{eV}$; PLQY 依次增加, 化合物 O4 最大, 为 $96 \%$. 以这四种材 料为发光客体, 器件结构采用 $\mathrm{ITO} / \mathrm{NPB}(30 \mathrm{~nm}) / \mathrm{TAPC}$ $(20 \mathrm{~nm}) / \mathrm{mCBP}: \operatorname{Dopant}(30 \mathrm{~nm}) / \mathrm{PPT}(10 \mathrm{~nm}) / \mathrm{TmPyPb}(60$ $\mathrm{nm}) / \mathrm{LiF}(0.8 \mathrm{~nm}) / \mathrm{Al}(100 \mathrm{~nm})$ 制备得到 OLED. 01 到 $\mathrm{O} 4$ 对应各项器件性能参数都依次得到了明显的提升, 并且 $\mathrm{EL}$ 光谱的最大发射波长也逐渐红移. 其中基于 01 的 OLED 呈深蓝光发射, 其余为天蓝光. 04 对应的 $\mathrm{EQE}_{\text {max }}$ 为 $23.9 \%$, 发射波长为 $485 \mathrm{~nm}, \mathrm{CIE}$ 色坐标为 $(0.19,0.32)$. 
同年，该课题组 ${ }^{[87]}$ 报道了两种 D-A-D 型 TADF 分子 O5 和 O6 (图 10). 由于分子内存在强的空间相互作用, 使两种分子获得较低的 $\Delta E_{\mathrm{ST}}$ 值, 分别为 $0.03 \mathrm{eV}$ 和 0.04 $\mathrm{eV}$. 叔丁基的引入使得 HOMO 能级提高而 LUMO 能级 几乎不受影响, 带隙明显减小, 吸收光谱和发射光谱都 产生一定的红移. 同时, O6 表现出比 05 更优异的热和 电化学稳定性. 以双[4-(9-氢-咔唑基)苯基]硫砜(CzPS) 为主体材料, TADF 分子掺杂浓度为质量分数 $5 \%$ 制备的 OLED 器件，二者都表现出超过 20\%的较高 EQE, O5 表 现出蓝光发射, 而 $\mathrm{O6}$ 则为绿光发射. 另外, 两者较小的 $\Delta E_{\mathrm{ST}}$ 值抑制了分子的非辐射衰变, 其 OLED 器件性能在 较高的亮度下仍然保持较高水平, 表现出较低的效率滚 降.

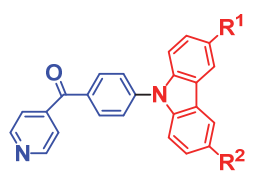

01: $R^{1}=R^{2}=H$

O2: $R^{1}=R^{2}=B u$

O3: $\mathrm{R}^{1}=\mathrm{Cz}, \mathrm{R}^{2}=\mathrm{H}$

O4: $R^{1}=R^{2}=C z$

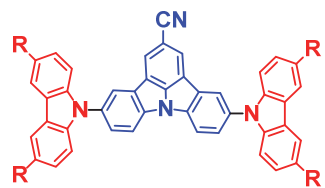

O7: $\mathbf{R}=\mathbf{H}$

O8: $R=B u$

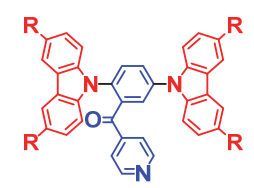

O5: $\mathbf{R}=\mathbf{H}$

O6: $R=B u$

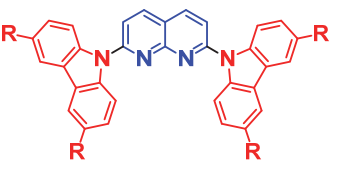

O9: $R=H$

010: $R=B u$
图 10 含其他类受体的 TADF 分子

Figure 10 Carbazole-based TADF molecules with other acceptor

为探索更多适用于深蓝光发射的电子受体, Lee 等 ${ }^{88}$ 将氰基修饰的吲哚并咔唑(IC)作为电子受体、咔唑 基团为电子给体合成了两种深蓝光 TADF 分子 07 和 O8 (图 10). 由于叔丁基咔唑的给电子能力比咔唑强, 因此基于叔丁基咔唑给体的 07 分子显示出较低的 $\Delta E_{\mathrm{ST}}$ $(0.19 \mathrm{eV})$ 和更小的带隙 $(2.81 \mathrm{eV})$, 同时发现引入的叔丁 基不会对 PLQY 和延迟寿命产生明显的影响. 以 DPEPO 作为主体材料, TADF 分子掺杂浓度为质量分数 $10 \%$ 的发射层结构制备了 OLED 器件, 两者均呈深蓝光 发射, 叔丁基会阻碍分子间载流子的迁移, 注入的载流 子在发射层中形成激子, 因此会提高发光器件的发光亮 度和电流密度. 此外, 叔丁基取代基同样对 EQE、PE、 $\mathrm{CE}$ 等器件性能都有所提升, 最终 $\mathrm{O8}$ 对应的器件的 $\mathrm{EQE}_{\text {max }} 、 \mathrm{PE}_{\max }$ 和 $C E_{\text {max }}$ 分别为 $16.0 \% 、 13.4 \mathrm{~lm} \cdot \mathrm{W}^{-1}$ 和 $17.2 \mathrm{~cd} \bullet \mathrm{A}^{-1}$. 需要注意的是叔丁基在提高各项主要性能 指标的同时, 器件发光色纯度均存在一定的损失, 色坐 标的 $y$ 值由原来的 0.08 增加到 0.13 .
为了获得高效电致蓝光发射, 近来 Chen 课题组 ${ }^{[89]}$ 分别以叔丁基修饰的咔坐和萗啶为电子给、受体合成了 两种 TADF 分子 09 和 O10(图 10). 他们发现叔丁基的 引入会造成非对称的分子结构, 进而导致 $\Delta E_{\mathrm{ST}}$ 降低, 同 时削弱了分子间作用力和消除 DET (dexter energy transfer), 有效抑制激子猝灭进而提高 PLQY, O10 具有 $0.14 \mathrm{eV}$ 的 $\Delta E_{\mathrm{ST}}$ 和 $67.5 \%$ 的 PLQY. 以 DPEPO 作为主体 材料, TADF 分子掺杂浓度为质量分数 $20 \%$ 制备了 OLED 器件, 二者均呈现蓝光发射. 器件性能对比发现, 叔丁基使得器件的 $\mathrm{EQE} 、 \mathrm{PE} 、 \mathrm{CE}$ 和亮度等性能参数全 面提升, 但色纯度有所下降. 基于化合物 $\mathbf{O 1 0}$ 的发光器 件的 $\mathrm{EQE}_{\max }$ 为 $20.9 \% 、 \mathrm{PE}_{\max }$ 为 $26.5 \mathrm{~lm} \cdot \mathrm{W}^{-1} 、 \mathrm{CE}_{\max }$ 为 $35.9 \mathrm{~cd} \cdot \mathrm{A}^{-1} 、 L_{\max }$ 为 $3684 \mathrm{~cd} \cdot \mathrm{m}^{-2}$ 、 $\mathrm{CIE}$ 色坐标为 $(0.15$, $0.22)$.

\section{4 多重共振型 TADF 分子的取代基效应}

在基于 TADF 材料的 OLED 中, $\mathrm{S}_{1}$ 和 $\mathrm{T}_{1}$ 之间具有小 的能级差 $\left(\Delta E_{\mathrm{ST}}\right)$ 是 RISC 过程有效进行的保障. 最小化 $\Delta E_{\mathrm{ST}}$ 的常见策略是引入电子供体与受体, 使得分子的 HOMO 和 LUMO 有效分离, 并减小处于激发态的单占 据分子轨道(SOMO)之间的交换相互作用. 然而这种策 略增强了激发态的结构弛豫, 并增加了斯托克斯位移, 导致 EL 光谱峰形变宽, 而峰形的加宽不利于色纯度的 提升并极大地降低了其 $\mathrm{EQE}^{[90]}$. 为了克服这些问题, Ikuta 等[90]创造性地提出了特殊解决方案, 报道了一类 基于氮嗍的刚性杂环的多重共振效应的 TADF (MR-TADF)发光材料 MR1(图 11). 与 D-A 型 TADF 发 射体不同, 这些 MR-TADF 分子结构刚性更强, 并通过 氮和硝原子的相反共振效应实现 HOMO 和 LUMO 分离.

Liang 等[91]为了解决化合物 $\mathbf{M R 1}^{[90]}$ 分子的较大斯 托克斯位移和严重效率滚降等问题, 设计合成了 MR-TADF 材料 MR2 (图 11). 在化合物 MR1 骨架中引 入的叔丁基咔唑单元和叔丁基可以提高共振效应和光 致发光量子产率，同时保证其色纯度. 研究发现取代基 的引入会减少 TTA 和其他非辐射过程, 提高振子强度 $f$ 从而获得 $97.48 \%$ 的高 PLQY 值和较高的 RISC 速率. 以 MR2 为发光客体, 2,6-DCzppy 为主体材料制备 OLED 器 件, 其 FWHM 仅 $27 \mathrm{~nm}, \mathrm{EQE}_{\max }$ 达 $32.1 \%, L_{\max }$ 为 16593 $\mathrm{cd} \cdot \mathrm{m}^{-2}, \mathrm{CE}_{\text {max }}$ 和 $\mathrm{PE}_{\text {max }}$ 也得到了显著提高, 分别为 40.2 $\mathrm{cd} \cdot \mathrm{A}^{-1}$ 和 $30.0 \mathrm{~lm} \cdot \mathrm{W}^{-1}$. 即使在 $100 \mathrm{~cd} \cdot \mathrm{m}^{-2}$ 的亮度下, $\mathrm{EQE}$ 仍高达 $27.4 \%$, 是当时性能最优异的蓝色 TADF-OLED 之一.

MR-TADF 具有优异的色纯度, 但 N/B 共振体系也 存在效率滚降严重等问题. Jiang 等 ${ }^{[92]}$ 成功开发出 N/O 体 系的 MR-TADF 分子 QAD (化合物 MR3). 这也是迄今 为止报道的最小 $\mathrm{TADF}$ 发射体. 基于化合物 MR3 的纯 蓝色 OLED 实现了 $19.4 \%$ 的 $\mathrm{EQE}_{\max }$, 并且 FWHM 仅为 $39 \mathrm{~nm}$. 同年 Zhang 等[93]在化合物 MR3 分子骨架中引入 


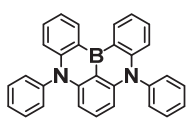

MR1

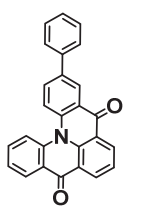

MR4
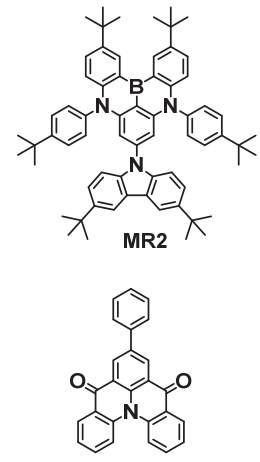

MR5

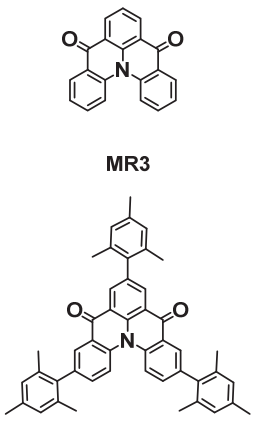

MR6

图 11 多重共振型 TADF 分子

Figure 11 Multiple resonance TADF molecules

苯基, 设计合成了两种 MR-TADF 分子 MR4 和 MR5 (图 11 ), 发现不同位置的苯环取代基可改变分子的对称性 (MR4 分子结构发生变化, 而 MR5 分子结构无变化), 从而扰乱 QAD 分子骨架上前线分子轨道的分布, 最终 影响弛豫过程. 此外, 苯环取代的位置不同对荧光光谱 的 FWHM 影响也有所不同, MR5 和 MR4 对应的 FWHM 分别为 $22 \mathrm{~nm}$ 和 $30 \mathrm{~nm}$. 尽管二者具有几乎一样的 $\Delta E_{\mathrm{ST}}$, 但其掺杂薄膜延迟寿命差异较大, MR4 和 MR5 的 $\tau_{\mathrm{d}}$ 分 别 $250 \mu \mathrm{s}$ 和 $474 \mu \mathrm{s}$. 以 $\mathrm{mCP}$ 为主体材料, 掺杂质量分数 $2 \% \mathrm{TADF}$ 材料作为发光层, 结构采用 ITO/TAPC (35 $\mathrm{nm}) / \mathrm{TCTA}(10 \mathrm{~nm}) / \operatorname{EML}(20 \mathrm{~nm}) / \operatorname{TmPyPB}(40 \mathrm{~nm}) / \mathrm{LiF}(1$ $\mathrm{nm}) / \mathrm{Al}$ 制备得到了 OLED 器件, 两种器件均呈蓝光发 射. 虽然两种器件具有相近的 $\mathrm{CE}_{\max } 、 \mathrm{PE}_{\max }$ 和 $\mathrm{EQE}_{\max }$, 但基于 MR5 的器件色纯度更优, 其 $\lambda_{\mathrm{EL}}$ 为 $472 \mathrm{~nm}$, $\mathrm{FWHM}$ 为 $34 \mathrm{~nm}$ 以及 CIE 色坐标为 $(0.12,0.24)$; 而基于 MR4 的器件发光亮度更大, 最高达 $4975 \mathrm{~cd} \cdot \mathrm{m}^{-2}$. 此外, 发现不论苯基取代基的引入位置是 3 号位还是 7 号位, $\mathrm{EL}$ 光谱以及 CIE 色坐标都会产生一定的红移, 同时发 光亮度约是原来的 3 倍和 5 倍.

近来, Olivier 团队 ${ }^{[94]}$ 在化合物 MR3 的外围修饰了 三甲苯基取代基得到化合物 MR6 (图 11). 研究发现三 甲苯基可以减轻 MR-TADF 分子中的聚集猝灭效应，从 而使得 MR6 掺杂薄膜获得更高的 PLQY. 三甲苯基的引 入会增加分子的共轭程度, 使得其苂光光谱产生一定的 红移, 同时材料的电化学和热稳定性明显提高. 另外也 会导致分子掺杂薄膜的 $\mathrm{S}_{1}$ 和 $\mathrm{T}_{1}$ 略微降低, 但其能级差 $\Delta E_{\mathrm{ST}}$ 与取代前的几乎保持一致. 基于 $\mathrm{MR3}$ 和 MR6 设计 的 TADF 蓝光 OLED 结构为 ITO/HAT-CN(10 nm)/TAPC $(40 \mathrm{~nm}) / \mathrm{TCTA}(10 \mathrm{~nm}) / \mathrm{mCP}: \operatorname{guest}(w=3.5 \%, 20 \mathrm{~nm}) /$ $\mathrm{TmPyPb}(50 \mathrm{~nm}) / \mathrm{LiF}(1 \mathrm{~nm}) / \mathrm{Al}(100 \mathrm{~nm})$, 发现三甲苯基 虽然会导致 EL 光谱和色坐标红移, 但能够降低 FWHM, 提高亮度和 $\mathrm{EQE}$, 其 $L_{\max }$ 达 $12949 \mathrm{~cd} \bullet \mathrm{m}^{-2}, \mathrm{EQE}_{\max }$ 为 $21.1 \%$.

上述的蓝光 MR-TADF 分子及其 OLED 器件光电性 质数据列于表 $2 . M R-T A D F$ 蓝光材料具有的优异色纯度

和发光效率，引起众多学者的广泛关注. 为了克服自身 的不足，除了通过取代基效应改善材料性能外，Duan 等 ${ }^{[95]}$ 提出了热活化敏化荧光(TSF)发光机制. Adachi 等[96]基于 TADF 与超苂光技术制备了高效率、高稳定性 的纯蓝光 OLED. 这些工作都为蓝光 MR-TADF 材料的 开发和高性能蓝光 OLED 的研制提供了新思路.

\section{5 总结与展望}

综上所述，本文概述了 D-A 型和多重共振型蓝光 $\mathrm{TADF}$ 分子的取代基引入对材料分子的物化性质和电致 发光器件性能的影响. 对于 D-A 型 TADF 分子, 不同取 代基可分别引入至分子的电子给体、共轭桥和电子受体. 常见取代基如甲基、叔丁基、苯基等多为给电子基团，拉 电子基团如三氟甲基等则较为少见. 一般, 在 D-A 型 TADF 分子的供体单元上引入取代基会使得荧光光谱会 产生一定的红移, 器件性能整体有所提高, 但 CIE 色坐 标也会相应地红移. 在桥连单元引入取代基常会造成较 大的分子扭曲和结构刚性, 从而减小 $\Delta E_{\mathrm{ST}}$ 和降低 $\tau_{\mathrm{d}}$, 进 而获得较高的 RISC 速率, 最终使得器件 EL 光谱蓝移, 表现出较好的色纯度. 对于相关电子受体基团上的取代 基效应，发现取代基可以调节受体单元的吸电子能力, 常会影响分子的 LUMO 能级, 增大分子带隙从而导致 发射蓝移; 对于器件性能, 能够提升色纯度, 但不同的 取代基对器件的其他性能影响不一. 对于多重共振型 TADF 分子, 在共振骨架外围修饰取代基, 不影响共振 机理的前提下往往能够抑制聚集导致的猝灭，提高材料 的稳定性, 提升器件的 $\mathrm{EQE}$ 和亮度等性能参数.

尽管蓝光 TADF 小分子材料的开发已取得了长足的 进展, 但要达到高效稳定可商业化的标准尚需更深一步 研究探索. 一方面, 设计开发新型的取代基结构, 精准 优化和微调 TADF 小分子的物化特性、电子结构和聚集 态结构等, 从而有效提升器件的综合性能; 另一方面则 是需要结合现有或新开发的取代基, 发展新型高效蓝光 $\mathrm{TADF}$ 分子，协同促进器件性能提升; 发掘并结合新的 发光机理和采用合适的器件新结构、新工艺等也是未来 基于 TADF 小分子的蓝光 OLED 研究的重要方向. 另外, 对于蓝光 TADF 稳定性的提高一般可以从以下角度进行 考虑. 首先分子需要具有足够的刚性和分子量, 以保证 其良好的热稳定性. 其次应减少分子的电化学活性位 点, 避免在电激励下发生电聚合和交联等不利反应，提 高分子的电学惰性. 再者可以通过在分子上引入非平面 空间位阻，引入抗氧化受阻胺光稳定剂和构造拓扑结构 等策略提高分子的光化学稳定性. 综合考虑这三方面因 素, 将有助于高效稳定蓝光 TADF 分子的开发和高性能 蓝光器件的研制. 最后, 蓝光 TADF 小分子的深入研究 和商业化必将极大地推动蓝光 TADF 聚合物及其溶液法 加工器件的发展，推进相关柔性照明和信息显示等技术 实用化. 
表 2 TADF 分子 MR1 MR6 的热学、光物理性质和 OLED 器件性能

Table 2 Thermal and photophysical properties and OLED performance of TADF molecule MR1 $\sim$ MR6

\begin{tabular}{|c|c|c|c|c|c|c|c|c|c|}
\hline Emitter & $\begin{array}{c}T_{\mathrm{g}} / T_{\mathrm{d}} \\
/{ }^{\circ} \mathrm{C}\end{array}$ & $\lambda_{\mathrm{PL}} / \mathrm{nm}$ & $\begin{array}{l}\mathrm{PLQY}^{c} / \% \\
\text { (Sol./film) }\end{array}$ & $\Delta E_{\mathrm{ST}} / \mathrm{eV}$ & $\mathrm{FWHM} / \mathrm{nm}$ & $\lambda_{\mathrm{EL}} / \mathrm{nm}$ & CIE & $\mathrm{EQE} / \%$ & Ref. \\
\hline MR1 & $-/-$ & $460^{a}$ & $88.00 \mathrm{~d} /-$ & $0.20^{a, e}$ & 28 & 459 & $(0.13,0.09)$ & 20.2 & [90] \\
\hline MR2 & $-/ 406$ & $470^{a}$ & $97.48 \mathrm{~d} /-$ & $0.14^{a, e}$ & 27 & 474 & $(0.12,0.19)$ & 32.1 & [91] \\
\hline MR3 & $-/ 323$ & $453^{a}$ & $-/ 72.4$ & $0.18^{a, e}$ & 39 & 468 & $(0.13,0.18)$ & 19.4 & [92] \\
\hline MR4 & $-/ 391$ & $466^{a}$ & $-/ 73$ & $0.18^{b, e}$ & 44 & 480 & $(0.13,0.32)$ & 19.1 & [93] \\
\hline MR5 & $-/ 399$ & $464^{a}$ & $-/ 68$ & $0.19^{b, e}$ & 34 & 472 & $(0.12,0.24)$ & 18.7 & [93] \\
\hline MR6 & $-/ 437$ & $468^{a}$ & $37 / 80$ & $0.21^{b, e}$ & 36 & 480 & $(0.12,0.32)$ & 21.1 & [94] \\
\hline
\end{tabular}

${ }^{a}$ Dispersed in solution; ${ }^{b}$ dispersed in a host film; ${ }^{c}$ under $\mathrm{N}_{2}$ conditions; ${ }^{d}$ absolute PLQY from integrating sphere measurement; ${ }^{e}$ calculated from the PL measurement.

\section{作者简介}

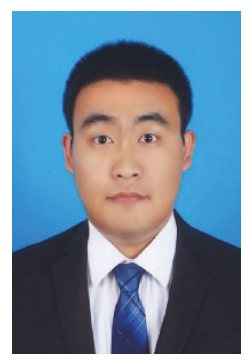

周涛, 南京邮电大学信息材料与纳米技术研究院/材料科 学与工程学院 2019 级研究生, 导师为冯全友副教授. 主要从 事有机发光材料的设计合成及其性能研究.

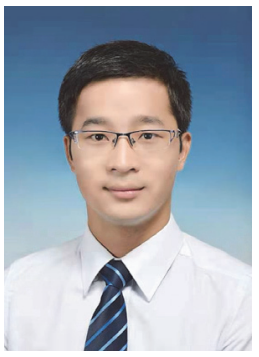

冯全友, 南京邮电大学材料科学与工程学院副教授、硕士 生导师. 2005 至 2009 年就读于西南大学化学与化工学院, 获 得学士学位. 2009 至 2014 年就读于复旦大学先进材料实验室, 获得博士学位 (导师: 周刚教授、王忠胜教授). 随后加入南京 邮电大学信息材料与纳米技术研究院/材料科学与工程学院. 2015 至 2017 年在弗吉尼亚理工大学从事博士后研究 (导师: Tong Rong 教授). 目前主要研究方向为有机/聚合物宽带隙半 导体材料及其光电子器件.

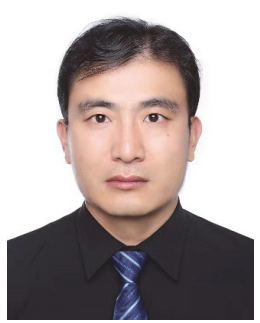

解令海, 南京邮电大学信息材料与纳米技术研究院/材料 科学与工程学院教授、博士生导师, 国家自然科学基金优秀青 年科学基金获得者. 2000 年和 2003 年分别获得东北师范大学 学士学位和汕头大学硕士学位. 2003 至 2006 年就读于复旦大
学先进材料研究院, 获得博士学位(导师: 黄维院士). 长期从 事多功能有机半导体材料的设计合成及其在有机发光、有机 激光、有机存储和忆阻器等领域的应用研究.

\section{References}

[1] Tang, C. W.; VanSlyke, S. A. Appl. Phys. Lett. 1987, 51, 913.

[2] Burroughes, J. H.; Bradley, D. D. C.; Brown, A. R.; Marks, R. N.; Mackay, K.; Friend, R. H.; Burns, P. L.; Holmes, A. B. Nature 1990, $347,539$.

[3] Feng, Q.-Y.; Li, B.; Zuo, Z.-Y.; Xie, S.-L.; Yu, M.-N.; Liu, B.; Wei, Y.; Xie, L.-H.; Xia, R.-D.; Huang, W. Chin. J. Polym. Sci. 2019, 37, 11.

[4] Bian, Y.; Liu, K.; Guo, Y.; Liu, Y. Acta Chim. Sinica 2020, 78, 848 (in Chinese). (边洋爽, 刘凯, 郭云龙, 刘云圻, 化学学报, 2020, 78,848 .)

[5] Ma, Y.; Zhang, H.; Shen, J.; Che, C. Synth. Met. 1998, 94, 245.

[6] Baldo, M. A.; O'Brien, D. F.; You, Y.; Shoustikov, A.; Sibley, S.; Thompson, M. E.; Forrest, S. R. Nature 1998, 395, 151.

[7] Wang, Z. Q.; Cai, J. L.; Zhang, M.; Zheng, C. J.; Ji, B. M. Acta Chim. Sinica 2019, 77, 263 (in Chinese). (王志强, 蔡佳林, 张明, 郑才俊, 吉保明, 化学学报, 2019, 77, 263.)

[8] Su, S.-J.; Gonmori, E.; Sasabe, H.; Kido, J. Adv. Mater. 2008, 20 , 4189.

[9] Ly, K. T.; Chen-Cheng, R.-W.; Lin, H.-W.; Shiau, Y.-J.; Liu, S.-H.; Chou, P.-T.; Tsao, C.-S.; Huang, Y.-C.; Chi, Y. Nat. Photonics 2017, 11,63 .

[10] Wang, Y. K.; Sun, Q.; Wu, S. F.; Yuan, Y.; Li, Q.; Jiang, Z. Q.; Fung, M. K.; Liao, L. S. Adv. Funct. Mater. 2016, 26, 7929.

[11] Zou, J.; Wu, H.; Lam, C. S.; Wang, C.; Zhu, J.; Zhong, C.; Hu, S.; Ho, C. L.; Zhou, G. J.; Wu, H.; Choy, W. C. H. Adv. Mater. 2011, 23, 2976.

[12] Ma, Y.; Chen, K. X.; Guo, Z. L.; Liu, S. J.; Zhao, Q.; Wong, W. Y. Acta Chim. Sinica 2020, 78, 23 (in Chinese). (马云, 陈可欣, 郭则 灵, 刘淑娟, 赵强, 黄维扬, 化学学报, 2020, 78, 23.)

[13] Ren, B.-Y.; Yi, J.-C.; Zhong, D.-K.; Zhao, Y.-Z.; Guo, R.-D.; Sheng, Y.-G.; Sun, Y.-G.; Xie, L.-H.; Wei, H. Acta Chim. Sinica 2020, 78, 56 (in Chinese). (任保轶, 依建成, 钟道昆, 赵玉志, 郭闰达, 盛永 刚, 孙亚光, 解令海, 黄维, 化学学报, 2020, 78, 56.)

[14] Liang, X.; Tu, Z.-L.; Zheng, Y.-X. Chem. Eur. J. 2019, 25, 5623.

[15] Duan, L.; Qiu, Y. Chin. J. Mater. Res. 2015, 29, 321 (in Chinese). (段炼, 邱勇, 材料研究学报, 2015, 29, 321.)

[16] Uoyama, H.; Goushi, K.; Shizu, K.; Nomura, H.; Adachi, C. Nature 2012, 492, 234

[17] Adachi, C. SID Symposium Digest of Technical Papers, Blackwell Publishing Ltd., Oxford, UK, 2013, pp. 513 $\sim 514$.

[18] Liu, W.; Chen, J. X.; Zheng, C. J.; Wang, K.; Chen, D. Y.; Li, F.; Dong, Y. P.; Lee, C. S.; Ou, X. M.; Zhang, X. H. Adv. Funct. Mater. 2016, 26, 2002.

[19] Zhang, J.; Ding, D.; Wei, Y.; Han, F.; Xu, H.; Huang, W. Adv. Mater 2016, 28, 479.

[20] Zhang, D.; Duan, L.; Li, C.; Li, Y.; Li, H.; Zhang, D.; Qiu, Y. Adv. Mater. 2014, 26, 5050.

[21] Zhang, D.; Cai, M.; Bin, Z.; Zhang, Y.; Zhang, D.; Duan, L. Chem. Sci. 2016, 7, 3355.

[22] Chen, J.-X.; Tao, W.-W.; Chen, W.-C.; Xiao, Y.-F.; Wang, K.; Cao, C.; Yu, J.; Li, S.; Geng, F.-X.; Adachi, C.; Lee, C.-S.; Zhang, X.-H. Angew. Chem. Int. Ed. 2019, 58, 14660. 
[23] Wu, T.-L.; Huang, M.-J.; Lin, C.-C.; Huang, P.-Y.; Chou, T.-Y.; Chen-Cheng, R.-W.; Lin, H.-W.; Liu, R.-S.; Cheng, C.-H. Nat. Photonics 2018, 12, 235.

[24] Ahn, D. H.; Kim, S. W.; Lee, H.; Ko, I. J.; Karthik, D.; Lee, J. Y.; Kwon, J. H. Nat. Photonics 2019, 13, 540.

[25] Cai, X.-Y.; Su, S.-J. Adv. Funct. Mater. 2018, 28, 1802558.

[26] Qiu, Z. P.; Tan, J. H.; Cai, N.; Wang, K.; Ji, S. M.; Huo, Y. P. Chin. J. Org. Chem. 2019, 39, 679 (in Chinese). (邱志鹏, 谭继华, 蔡宁, 王凯，籍少敏，霍延平，有机化学, 2019, 39, 679.)

[27] Liu, Q. Q.; Zhang, Y. H.; Gao, C.; Wang, T. Y.; Hu, W. P.; Dong, H. L. Acta Chim. Sinica 2020, 78, 945 (in Chinese). (刘情情, 张逸寒, 高灿, 王天禹, 胡文平, 董焕丽, 化学学报, 2020, 78, 945.)

[28] Qiu, Z.; Yang, Z.; Chen, W.-C.; Xing, L.; Hu, S.; Ji, S.; Yang, Q.; Cai, N.; Ouyang, X.; Huo, Y. J. Mater. Chem. C 2020, 8, 4139.

[29] Xie, L. H.; Chang, Y. Z.; Gu, J. F.; Sun, R. J.; Li, J. W.; Zhao, X. H.; Huang, W. Acta Phys.-Chim. Sin. 2010, 26, 1784 (in Chinese). (解令 海, 常永正, 顾菊芬, 孙瑞娟, 李杰伟, 赵祥华, 黄维, 物理化学 学报, 2010, 26, 1784.)

[30] Penfold, T. J.; Dias, F. B.; Monkman, A. P. Chem. Commun. 2018, $54,3926$.

[31] Dreuw, A.; Head-Gordon, M. Chem. Rev. 2005, 105, 4009.

[32] Byeon, S. Y.; Kim, J.; Lee, D. R.; Han, S. H.; Forrest, S. R.; Lee, J. Y. Adv. Opt. Mater. 2018, 6, 1701340 .

[33] Samanta, P. K.; Kim, D.; Coropceanu, V.; Brédas, J.-L. J. Am. Chem. Soc. 2017, 139, 4042.

[34] Gan, L.; Xu, Z.; Wang, Z.; Li, B.; Li, W.; Cai, X.; Liu, K.; Liang, Q.; Su, S.-J. Adv. Funct. Mater. 2019, 29, 1808088.

[35] Gómez-Bombarelli, R.; Aguilera-Iparraguirre, J.; Hirzel, T. D.; Duvenaud, D.; Maclaurin, D.; Blood-Forsythe, M. A.; Chae, H. S.; Einzinger, M.; Ha, D.-G.; Wu, T.; Markopoulos, G.; Jeon, S.; Kang, H.; Miyazaki, H.; Numata, M.; Kim, S.; Huang, W.; Hong, S. I.; Baldo, M.; Adams, R. P.; Aspuru-Guzik, A. Nat. Mater. 2016, 15, 1120.

[36] Parker, C. A.; Hatchard, C. G. Trans. Faraday Soc. 1961, 57, 1894.

[37] Gibson, J.; Monkman, A. P.; Penfold, T. J. ChemPhysChem 2016, $17,2956$.

[38] Chen, T.; Zheng, L.; Yuan, J.; An, Z.; Chen, R.; Tao, Y.; Li, H.; Xie, X.; Huang, W. Sci. Rep. 2015, 5, 10923.

[39] Kim, H. M.; Choi, J. M.; Lee, J. Y. RSC Adv. 2016, 6, 64133.

[40] Tao, Y.; Yuan, K.; Chen, T.; Xu, P.; Li, H.; Chen, R.; Zheng, C.; Zhang, L.; Huang, W. Adv. Mater. 2014, 26, 7931.

[41] Zhang, Q.; Kuwabara, H.; Potscavage, W. J.; Huang, S.; Hatae, Y.; Shibata, T.; Adachi, C. J. Am. Chem. Soc. 2014, 136, 18070.

[42] Zhang, Q.; Li, J.; Shizu, K.; Huang, S.; Hirata, S.; Miyazaki, H.; Adachi, C. J. Am. Chem. Soc. 2012, 134, 14706.

[43] Williams, E. L.; Li, J.; Jabbour, G. E. Appl. Phys. Lett. 2006, 89, 083506.

[44] Tan, J.-H.; Huo, Y.-P.; Cai, N.; Ji, S.-M; Li, Z.-Z.; Zhang, L. Chin. J. Org. Chem. 2017, 37, 2457 (in Chinese). (谭继华, 霍延平, 蔡宁, 籍少敏, 李宗植, 张力, 有机化学, 2017, 37, 2457.)

[45] Tan, J.-H.; Chen, W.-C.; Ni, S.-F.; Qiu, Z.; Zhan, Y.; Yang, Z.; Xiong, J.; Cao, C.; Huo, Y.; Lee, C.-S. J. Mater. Chem. C 2020, 8 , 8061.

[46] Huang, R.; Kukhta, N. A.; Ward, J. S.; Danos, A.; Batsanov, A. S.; Bryce, M. R.; Dias, F. B. J. Mater. Chem. C 2019, 7, 13224.

[47] Uoyama, H.; Goushi, K.; Shizu, K.; Nomura, H.; Adachi, C. Nature 2012, 492, 234.

[48] Park, W. J.; Lee, Y.; Kim, J. Y.; Yoon, D. W.; Kim, J.; Chae, S. H.; Kim, H.; Lee, G.; Shim, S.; Yang, J. H.; Lee, S. J. Synth. Met. 2015, 209, 99.

[49] Zhang, D.; Cai, M.; Zhang, Y.; Zhang, D.; Duan, L. Mater. Horiz. 2016, 3, 145 .

[50] Chan, C.-Y.; Cui, L.-S.; Kim, J. U.; Nakanotani, H.; Adachi, C. Adv. Funct. Mater. 2018, 28, 1706023.

[51] Noda, H.; Nakanotani, H.; Adachi, C. Sci. Adv. 2018, 4, eaao6910.

[52] Kreiza, G.; Berenis, D.; Banevičius, D.; Juršènas, S.; Javorskis, T.; Orentas, E.; Kazlauskas, K. Chem. Eng. J. 2021, 412, 128574.

[53] Chen, X. L.; Jia, J. H.; Yu, R.; Liao, J. Z.; Yang, M. X.; Lu, C. Z. Angew. Chem. Int. Ed. 2017, 56, 15006.

[54] Lee, Y. H.; Park, S.; Oh, J.; Woo, S.-J.; Kumar, A.; Kim, J.-J.; Jung, J.; Yoo, S.; Lee, M. H. Adv. Opt. Mater. 2018, 6, 1800385.

[55] Wu, T.-L.; Lo, S.-H.; Chang, Y.-C.; Huang, M.-J.; Cheng, C.-H. ACS Appl. Mater. Interfaces 2019, 11, 10768.

[56] Konidena, R. K.; Lee, J. Y. Chem. Rec. 2019, 19, 1499.

[57] Hirata, S.; Sakai, Y.; Masui, K.; Tanaka, H.; Lee, S. Y.; Nomura, H.; Nakamura, N.; Yasumatsu, M.; Nakanotani, H.; Zhang, Q.; Shizu,
K.; Miyazaki, H.; Adachi, C. Nat. Mater. 2015, 14, 330.

[58] Lee, D. R.; Kim, M.; Jeon, S. K.; Hwang, S. H.; Lee, C. W.; Lee, J. Y. Adv. Mater. 2015, 27, 5861.

[59] Cha, J.-R.; Lee, C. W.; Lee, J. Y.; Gong, M.-S. Dyes Pigm. 2016, 134, 562.

[60] Feng, Q. Y.; Tan, K. S.; Zheng, X. J.; Xie, S. L.; Xue, K.; Bo, Y.; Zhang, H.; Lin, D. Q.; Rao, J. F.; Xie, X. M.; Xie, L. H.; Cao, H. T.; Zhang, H. M.; Wei, Y.; Huang, W. ChemPhotoChem 2020, 4, 321.

[61] Guo, J.; Li, X.-L.; Nie, H.; Luo, W.; Hu, R.; Qin, A.; Zhao, Z.; Su, S.-J.; Tang, B. Z. Chem. Mater. 2017, 29, 3623.

[62] Lin, T.-A.; Chatterjee, T.; Tsai, W.-L.; Lee, W.-K.; Wu, M.-J.; Jiao, M.; Pan, K.-C.; Yi, C.-L.; Chung, C.-L.; Wong, K.-T.; Wu, C.-C. Adv. Mater. 2016, 28, 6976.

[63] Lee, D. R.; Choi, J. M.; Lee, C. W.; Lee, J. Y. ACS Appl. Mater. Interfaces 2016, 8, 23190.

[64] Zhu, X.-D.; Tian, Q.-S.; Zheng, Q.; Wang, Y.-K.; Yuan, Y.; Li, Y.; Jiang, Z.-Q.; Liao, L.-S. J. Lumin. 2019, $206,146$.

[65] Zhu, X.-D.; Tian, Q.-S.; Zheng, Q.; Tao, X.-C.; Yuan, Y.; Yu, Y.-J.; Li, Y.; Jiang, Z.-Q.; Liao, L.-S. Org. Electron. 2019, 68, 113.

[66] Ryoo, C. H.; Cho, I.; Han, J.; Yang, J.-h.; Kwon, J. E.; Kim, S.; Jeong, H.; Lee, C.; Park, S. Y. ACS Appl. Mater. Interfaces 2017, 9, 41413.

[67] Lv, X.; Huang, R.; Sun, S.; Zhang, Q.; Xiang, S.; Ye, S.; Leng, P.; Dias, F. B.; Wang, L. ACS Appl. Mater. Interfaces 2019, 11, 10758.

[68] Oh, C. S.; Han, S. H.; Lee, J. Y. J. Mater. Chem. C 2017, 5, 9106.

[69] Woo, S.-J.; Kim, Y.; Kwon, S.-K.; Kim, Y.-H.; Kim, J.-J. ACS Appl. Mater. Interfaces 2019, 11, 7199.

[70] Huang, W.; Einzinger, M.; Maurano, A.; Zhu, T.; Tiepelt, J.; Yu, C.; Chae, H. S.; Van Voorhis, T.; Baldo, M. A.; Buchwald, S. L. Adv. Opt. Mater. 2019, 7, 1900476.

[71] Lee, K. H.; Jeon, S. O.; Chung, Y. S.; Numata, M.; Lee, H.; Lee, E. K.; Kwon, E. S.; Sim, M.; Choi, H.; Lee, J. Y. J. Mater. Chem. C 2020, $8,1736$.

[72] Im, Y.; Kim, M.; Cho, Y. J.; Seo, J.-A.; Yook, K. S.; Lee, J. Y. Chem. Mater. 2017, 29, 1946.

[73] Yang, J. W.; Choi, J. M.; Lee, J. Y. Phys. Chem. Chem. Phys. 2016, 18,31330 .

[74] Jürgensen, N.; Kretzschmar, A.; Höfle, S.; Freudenberg, J.; Bunz, U. H. F.; Hernandez-Sosa, G. Chem. Mater. 2017, 29, 9154.

[75] Han, M.; Chen, Y.; Xie, Y.; Zhang, F.; Li, X.; Huang, A.; Fan, Y.; Fan, Y.; Gong, Y.; Peng, Q.; Li, Q.; Ma, D.; Li, Z. Cell Rep. Phys. Sci. 2020, 1, 100252.

[76] Stachelek, P.; Ward, J. S.; dos Santos, P. L.; Danos, A.; Colella, M.; Haase, N.; Raynes, S. J.; Batsanov, A. S.; Bryce, M. R.; Monkman, A. P. ACS Appl. Mater. Interfaces 2019, 11, 27125.

[77] Sun, Y.; Duan, L.; Zhang, D.; Qiao, J.; Dong, G.; Wang, L.; Qiu, Y. Adv. Funct. Mater. 2011, 21, 1881.

[78] Sasabe, H.; Gonmori, E.; Chiba, T.; Li, Y.-J.; Tanaka, D.; Su, S.-J.; Takeda, T.; Pu, Y.-J.; Nakayama, K.-i.; Kido, J. Chem. Mater. 2008, $20,5951$.

[79] Komatsu, R.; Sasabe, H.; Seino, Y.; Nakao, K.; Kido, J. J. Mater. Chem. C 2016, 4, 2274.

[80] Li, B.; Li, Z.; Hu, T.; Zhang, Y.; Wang, Y.; Yi, Y.; Guo, F.; Zhao, L. J. Mater. Chem. C 2018, 6, 2351.

[81] Park, I. S.; Komiyama, H.; Yasuda, T. Chem. Sci. 2017, 8, 953.

[82] Komatsu, R.; Ohsawa, T.; Sasabe, H.; Nakao, K.; Hayasaka, Y.; Kido, J. ACS Appl. Mater. Interfaces 2017, 9, 4742.

[83] Kulkarni, A. P.; Tonzola, C. J.; Babel, A.; Jenekhe, S. A. Chem. Mater. 2004, 16, 4556 .

[84] Zhang, Z.; Li, G.; Ma, Y.; Wu, F.; Tian, W.; Shen, J. Chin. J. Org. Chem. 2000, 20, 529 (in Chinese). (张志明, 李国文, 马於光, 吴 芳, 田文晶, 沈家骢, 有机化学, 2000, 20, 529.)

[85] Wong, M. Y.; Krotkus, S.; Copley, G.; Li, W.; Murawski, C.; Hall, D.; Hedley, G. J.; Jaricot, M.; Cordes, D. B.; Slawin, A. M. Z.; Olivier, Y.; Beljonne, D.; Muccioli, L.; Moral, M.; Sancho-Garcia, J.-C.; Gather, M. C.; Samuel, I. D. W.; Zysman-Colman, E. ACS Appl. Mater. Interfaces 2018, 10, 33360.

[86] Rajamalli, P.; Senthilkumar, N.; Gandeepan, P.; Ren-Wu, C. C.; Lin, H. W.; Cheng, C. H. ACS Appl. Mater. Interfaces 2016, 8, 27026.

[87] Rajamalli, P.; Senthilkumar, N.; Gandeepan, P.; Huang, P.-Y.; Huang, M.-J.; Ren-Wu, C.-Z.; Yang, C.-Y.; Chiu, M.-J.; Chu, L.-K.; Lin, H.-W.; Cheng, C.-H. J. Am. Chem. Soc. 2016, 138, 628.

[88] Im, Y.; Han, S. H.; Lee, J. Y. J. Mater. Chem. C 2018, 6, 5012.

[89] Shen, Y.-F.; Zhao, W.-L.; Lu, H.-Y.; Wang, Y.-F.; Zhang, D.-W.; Li, M.; Chen, C.-F. Dyes Pigm. 2020, 178, 108324.

[90] Hatakeyama, T.; Shiren, K.; Nakajima, K.; Nomura, S.; Nakatsuka, 
S.; Kinoshita, K.; Ni, J.; Ono, Y.; Ikuta, T. Adv. Mater. 2016, 28 , 2777.

[91] Liang, X.; Yan, Z.-P.; Han, H.-B.; Wu, Z.-G.; Zheng, Y.-X.; Meng, H.; Zuo, J.-L.; Huang, W. Angew. Chem. Int. Ed. 2018, 57, 11316.

[92] Yuan, Y.; Tang, X.; Du, X.-Y.; Hu, Y.; Yu, Y.-J.; Jiang, Z.-Q.; Liao, L.-S.; Lee, S.-T. Adv. Opt. Mater. 2019, 7, 1801536.

[93] Li, X.; Shi, Y.-Z.; Wang, K.; Zhang, M.; Zheng, C.-J.; Sun, D.-M.; Dai, G.-L.; Fan, X.-C.; Wang, D.-Q.; Liu, W.; Li, Y.-Q.; Yu, J.; Ou, X.-M.; Adachi, C.; Zhang, X.-H. ACS Appl. Mater. Interfaces 2019, 11,13472 .
[94] Hall, D.; Suresh, S. M.; dos Santos, P. L.; Duda, E.; Bagnich, S.; Pershin, A.; Rajamalli, P.; Cordes, D. B.; Slawin, A. M. Z.; Beljonne, D.; Köhler, A.; Samuel, I. D. W.; Olivier, Y.; Zysman-Colman, E. Adv. Opt. Mater. 2020, 8, 1901627.

[95] Zhang, D.; Song, X.; Gillett, A. J.; Drummond, B. H.; Jones, S. T. E.; Li, G.; He, H.; Cai, M.; Credgington, D.; Duan, L. Adv. Mater 2020, 32, 1908355

[96] Chan, C.-Y.; Tanaka, M.; Lee, Y.-T.; Wong, Y.-W.; Nakanotani, H.; Hatakeyama, T.; Adachi, C. Nat. Photonics 2021, 15, 203.

(Cheng, B.) 